\title{
Global food safety as a complex adaptive system: key concepts and future prospects
}

\author{
by Nayak, R. and Waterson, P.
}

Copyright, publisher and additional information: This is the authors accepted manuscript. The final published version (version of record) is available online via Elsevier.

This version is made available under the CC-BY-ND-NC licence:

https://creativecommons.org/licenses/by-nc-nd/4.0/legalcode

Please refer to any applicable terms of use of the publisher

DOI: https://doi.org/10.1016/j.tifs.2019.07.040 


\title{
Global Food Safety as a Complex Adaptive System: Key Concepts and Future Prospects
}

\author{
Rounaq Nayak* and Patrick Waterson**
}
${ }^{*}$ Food Technology and Innovation Department, Harper Adams University, Newport TF10 8NB, UK
${ }^{* * H u m a n ~ F a c t o r s ~ a n d ~ C o m p l e x ~ S y s t e m s ~ G r o u p, ~ L o u g h b o r o u g h ~ D e s i g n ~ S c h o o l, ~}$ Loughborough University, Loughborough LE11 3TU, UK

6 Corresponding author: Rounaq Nayak. Tel: +44 (0)1952 820280 . E-mail:

7 RNayak@harper-adams.ac.uk. Address: G43, Jubilee Adams Building, Food

Technology and Innovation Department, Harper Adams University, Newport TF10 29 8NB, Shropshire, UK. 


\title{
Global Food Safety as a Complex Adaptive System: Key Concepts and Future Prospects
}

\author{
Abstract
}

Background

Over the last few decades the food production, distribution and consumption chains have become complex as a result of globalisation and food travelling over large distances. The food supply chain is a multi-layered structure with multiple interactions across and within the hierarchical levels across the entire food system. As unwanted factors and food safety behaviours could lead to global food poisoning catastrophes, it is important to adopt a systems approach to gain a whole-system perspective of the global food system.

\section{Scope and Approach}

In this review the importance of adopting a complex systems approach towards the global food system and a possible systems analysis method that would help capture this perspective are described. This study emphasizes the importance of adopting a proactive approach, starting with identifying the similarities between the characteristics of complex systems and the food system and the importance and benefits of adopting a whole system approach in the global food system.

\section{Key Findings and Conclusions}

Adopting a complex systems approach to the global food system is of paramount relevance as this would help further understand the interconnectivity of food systems and how multifaceted factors across systemic levels play a major role in achieving food safety. Using a systems analysis model such as the Systems-Theoretic Accident Models and Processes (STAMP) model provides the ability to tackle the limitations of event chain models and analyse the complex interactions among various components in the complex food system. It is the need of the hour to study food systems at micro and macro-levels and develop a model that would have the ability to identify food safety related issues across the global food system.

Key words: Complex systems; Globalisation; Food safety; Food safety system; Systems approach; Human Factors 


\section{Introduction}

66 Globalisation has led to a world-wide demand for a variety of food products and as a 67 direct consequence, food production, distribution and consumption chains have 68 become distributed, intricate and complex. A combination of population explosion and 69 food scarcity where more than 800 million people remain food insecure (FAO, WFP, 70 \& IFAD, 2012), is another reason for the widespread export and import of food across 71 the world. By 2050-2052, it is projected that the global population will reach 8-9 billion 72 people, and at such a point, the dynamics between population, climate and diet would 73 have a more direct effect on the global food systems than what it is today (Lee, 2014; 74 Randers, 2012). A population's diet is determined by a complex interplay of social, 75 economic and technological forces (Schlosser, 2001; Johnston et al., 2014). The food 76 supply chain, from subsistence farmers to multinational food companies, can be 77 viewed as a multifaceted structure with multiple interactions across and within factors 78 distributed across hierarchical levels in the entire system. These intricate levels of 79 interactions are a result of globalization of the agri-food system (Busch, 2004; Inglis, 80 2016).

81 Products that were once only locally available are now easily available all over the 82 world (Busch, 1997). This has brought together large populations who lived within 83 defined boundaries by introducing complex governance to deliver sufficient quantities 84 and quality of food (Hueston \& McLeod, 2012). Food safety policies help to orient local, 85 regional, national and global food systems. These policies are formed as a result of 86 interactions between a set of stakeholders, some, if not all of who might seek to defend 87 either theirs or their allies' interests (Maetz, 2013a). The degree of influence of each 88 stakeholder depends on their capacity to have an impact on the institutional framework 89 at the regional, national and global levels within which the policies are being 90 formulated. Governments at various levels often tend to make policies in favour of the 91 vast majority of the population that elected them and the private companies that invest 92 in their party (Maetz, 2013b; Pennington, 2003). The other relevant stakeholders are 93 multinational firms whose main objective is to maximise profit. These firms often have 94 a global impact as they operate in several countries at a time. Therefore, they provide 95 fiscal and social benefits to multiple governments and countries (Maetz, 2013b). 
96 Food regulations such as Regulation (EC) No 2073/2005 in the UK (Food Standards 97 Agency, 2005) and the Food Safety Modernization Act (FSMA) in the US (Food and 98 Drug Administration, 2015) make it mandatory for all food businesses to complete 99 microbial testing of their premises as well as of high-risk food products. As a result, 100 there is a tendency to rely solely on microbial analyses (Griffith et al., 2017). Although 101 such reactive preventative methods produce a safe food supply system in the short102 run, it is limited in its scope over the medium to long-term. Food poisoning outbreaks 103 are still a global issue; every year, millions of people get ill, thousands require 104 hospitalization and hundreds die from food-related illnesses (Walczak \& Reuter, 2002). 105 It was estimated by the World Health Organisation's Foodborne Disease Burden 106 Epidemiology Reference Group that in 2010, there were 582 million reported cases 107 and 251,000 reported deaths associated with 22 different foodborne enteric diseases 108 (WHO FERG group, 2015). The reason for this is the narrow microbiological base on 109 which preventative efforts are based. Processes such as time and temperature control, 110 safe food handling procedures, employee hygiene, cleaning and sanitizing techniques 111 and a Hazard Analysis and Critical Control Point (HACCP) plan or a HACCP-based 112 plan are proven to be effective (Walczak \& Reuter, 2002). Despite the existence of 113 reactive approaches, the issue still remains - how to minimize population exposure to 114 foodborne pathogens? Concepts relevant to adopting proactive techniques such as 115 understanding the food system and stakeholders' behaviours and interactions can be 116 helpful in understanding how and why food safety violations occur.

117 Food systems are quite fragile. Events such as the 1996 E.coli O157 outbreak in 118 Scotland (Pennington, 1997), 2009 Godstone Farm E.coli 0157 outbreak in England 119 (Griffin, 2010), 2011 sprouted foods E.coli outbreak in Germany (World Health 120 Organization, 2011) and the 2018 E.coli outbreak in the United States of America 121 (Adam Bros. Farming, 2018; Centers for Disease Control and Prevention, 2019) 122 highlight the consequences of such fragility. With food traveling over larger distances 123 in the modern world, food safety related concerns are often raised. This has also led 124 to an increase in the number of factors in the food system that have responsibilities 125 and accountabilities. Due to globalisation of the food industry, it is essential to look at 126 the food system from a global perspective and to identify and address all the flawed 127 factors associated with the food system. Although stricter and more detailed 128 regulations have been established since the above mentioned food poisoning 
129 incidents under the assumption that there will be strict compliance, there is a general 130 lack of understanding of compliance and performance variability (Hollnagel, 2009) 131 within the food system.

132 1.1. Aims and objectives

133 The overall aim of this paper is to outline the complex systemic properties of the global 134 food system. The specific objectives of the paper are threefold:

135 1. To outline the properties of a complex system and demonstrate its relevance to the 136 global food system and food safety.

137 2. To outline the possible effects of globalisation of the food system on food safety 138 behaviours.

139 3. To illustrate the value of using systems analysis methods to understand interactions 140 between and the functioning of the components of the food system.

141 In what follows, we first detail the history of globalisation of the food industry followed 142 by a timeline indicating the development of food safety. The primary intention of the 143 timeline is to indicate major developments related to food safety. The timeline also

144 indicates a shift in consumption pattern from immediate consumption to storage and 145 preservation for extending the shelf-life in order to help prevent food poisoning related 146 illnesses and to carry out trade, i.e., export food locally, regionally, nationally and 147 globally. In the later sections of the paper, the properties of a complex system and the 148 relevance of these properties in the current global food system are discussed in great 149 detail. Finally, we discuss a systems and control theory based model, STAMP 150 (System-Theoretic Accident Model and Processes), its properties, general application 151 and its possible applicability to understand the interactions between stakeholders 152 within the food system.

153

\section{2. Globalisation and the food industry}

155 There have been cascades of changes on a global scale since the latter decades of 156 the twentieth century (Gunderson \& Holling, 2002). The factors that played a role in 157 the globalisation of the food industry such as transition from local to global markets 
158

159

160

161

162

163

164

165

166

167

168

169

170

171

172

173

174

175

176

177

178

179

180

181

182

183

184

185

186

187

188

189

and shipping of food products over long distances also played a major role in the development of the concept of food safety by reasons mentioned below (Busch, 1997; Hueston \& McLeod, 2012). Globalisation can also have a negative impact on the food industry - e.g., after the 1964 Salmonella typhi outbreak in Aberdeen caused by the consumption of canned sliced beef imported from Argentina, not only did tourism in Aberdeen drop, but there was also a reduction in the amount of corned beef consumed in the UK. This led to cattle raisers in countries specialized in exporting beef, such as Paraguay, Kenya and Tanganyika, suffering an economic loss (Pennington, 2003).

Food safety has evolved as a result of various practices carried out by people who interact with food in various forms in various stages of development and operations across the world. All these people have deemed the food they have handled as safe. Hence, food safety is dependent on the more or less predictable behaviour of chemical and biological entities as well as the behaviour of human beings who perform more or less predictable activities to achieve a certain level of food safety that is deemed acceptable by local and global standards. Thus, food safety is a socio-natural process (Busch, 2004).

\subsection{Transition from local/regional to global markets}

In today's world, food purchased at a store is mostly never entirely locally produced and consumed. Consumers have no idea about how or where the food gets produced and how it is transported from one place to another. Due to the lengthened networks, there is an absence of personal ties between consumers and producers and processors (Busch, 1997). Multinational producers, processors and retailers have deliberately discouraged the social dimensions of exchange. This has forced consumers to pick from the wealth of goods supplied. According to a report by Vasquez-Nicholson in 2015, one of the leading supermarkets in the UK stocks 40,000 product lines, of which 25,000 are food and beverage. Another leading supermarket store in the UK carries about 21,000 food and beverage items (Vasquez-Nicholson, 2015). In a supermarket, the process of retrieving goods involves locating them, placing them in carts, bringing them to checkout counters, placing them on conveyor belts and putting the purchased products in bags (Busch, 1997). This process has not changed much over the last 20 years, the only changes being certain advances in technology such as self-checkout counters and portable scanning machines. Face-to- 
190 face relationships exist higher up the food chain, for example, wholesalers always 191 know who their suppliers and customers are. However, when it comes to the extreme 192 ends of the process, relations become impersonal (Busch, 1997). It is also important 193 to acknowledge that locally produced food has become the foci of food self-sufficiency 194 among some consumers (Fang et al., 2018), therefore, it is important to understand 195 local food systems to establish the dynamics of interactions between the various 196 stakeholders of these food systems.

197 2.2. Industrialization of the food industry and the scale of production

198 Advances in technology and the aim to improve social organisations have helped 199 increase scale of production (Busch, 1997). The first carload of fruits and vegetables 200 was shipped eastward in 1869 and it was only a decade later that rail service permitted 201 wider marketing areas (Busch, 1997; Levenstein, 1988). This led to the relocation of 202 larger units away from metropolitan areas. Mechanization occurred in four areas in the 203 food system; (1) mechanization of agriculture; (2) mechanization of organic 204 substances; (3) mechanization of meat; and (4) mechanization of growth (e.g., artificial 205 egg fertilization) (Giedion, 1948).

206 In the late 1800s, the Parris abattoirs of La Villette had an individual stall for each 207 animal where each animal was slaughtered individually, whereas the abattoirs in 208 Chicago were fully automated (Busch, 1997; Giedion, 1948). The scale of production 209 has increased all over the world. Tomatoes were once a garden crop, but are now 210 grown in large hectares of lands in the Netherlands and in the US (United States 211 Department of Agriculture Economic Research Service, 2016). Kiwis which were 212 grown in China as lowly berries are now grown on farms in New Zealand, Italy and 213 the United States of America (Busch, 1997).

214 2.3. Modernisation of production practices and processing technologies

215 A rise in population has led to an increase in the demand for food (Hueston \& McLeod, 216 2012; Kirezieva et al., 2015; Reiher, 2012; WWF, 2016). Chickens that were once 217 raised as pin money by American farm women are now bred everywhere with 218 thousands of birds squeezed into small cages. This is also the case with cows and 219 hogs (Busch, 1997). In order to feed these animals and birds, feed containing exotic 220 nutrients were imported from all over the world in order to maximise growth and feed 
221 efficiency while trying to minimise cost. Addition of exotic nutrients could lead to new 222 disease vectors. This is the cause of Bovine Spongiform Encephalopathy (Busch, 223 1997) which led to a large crisis between 1986 and 1996 despite the best efforts of 224 regulators (Cassano-Piche et al., 2006).

225 Along with the modernisation of farm practices, there has also been a development in 226 the processing industry. Food processing is a post-harvest activity that adds value to 227 the agricultural product (Wilkinson, 2004). The sudden boom of the food processing 228 industry in the 1990s was caused by foreign direct investment (FDI) and this led to an 229 increased revenue and employment generation and development of new knowledge 230 and technology (Wilkinson, 2004). Canning was one of the first 'developments' in the 231 food processing industry. This enabled the mobility of a wide range of foods to different 232 parts of the world. New forms of food were also created because of this development 233 (e.g., the invention of condensed soups by Campbell's Soup Company) (Busch, 1997; 234 Levenstein, 1988). According to a report from the United States Department of 235 Agriculture Economic Research Service (2016), 59\% of the tomato consumption in the 236 US was canned.

237 2.4. Shipping of a variety of products over long distances

238 There are two issues with shipping food over long distances: (1) the distance and (2) 239 the food product shipped. If a ship does not have the required conditions, it is easy for 240 the food product to spoil. For example, during the 1880s in the US, beef was shipped 241 from stockyards in Chicago to slaughterhouses in New York and by the time the 242 journey was completed, most animals would lose weight or die (Busch, 1997). During 243 this period, butchers were aware of diseases related to cattle. Once refrigerated cars 244 were invented and regulations were amended such that trained food inspectors 245 inspected cattle, these butchers began getting lesser information.

246 2.5. Shift from supply-driven to demand-driven economies

247 Until the $20^{\text {th }}$ century, countries had supply-driven economies where they followed a 248 model of food self-sufficiency to ensure adequate domestic supplies of basic feedstuffs. 249 This model permitted an increased supply, thereby reducing the costs of food. 250 Countries that produced in excess used export markets and food aid programs 251 (Hueston \& McLeod, 2012). However, since the $20^{\text {th }}$ century, there has been a rise in 
252 consumer demand for food. A rise in demand for chicken led to the development of 253 the broiler industry. Certain parts of the world consume only white meat where chicken 254 feet is regarded as a waste product whereas in other parts of the world, chicken feet 255 and dark meat are considered a delicacy. Global food trade has provided suppliers the 256 opportunity to supply all parts of the animals they breed whether or not there is any 257 domestic demand. The world enjoys relatively inexpensive food as commodities and 258 specialized products can be marketed worldwide (Hueston \& McLeod, 2012).

259

\section{3. Impact of globalization on food safety}

261 As mentioned in Section 2, factors that played a role in globalization also helped in 262 strengthening the conceptual framework required for food safety. Since food could not 263 be shipped over long distances or stored for large periods of time, investment was 264 made in the food preservation sector. The initial methods of food preservation involved 265 drying. This was a method known even in the ancient times. Fermentation and 266 pasteurization were the next developments in food preservation. The latter was 267 applied to wine in China (Hueston \& McLeod, 2012).

268 Canning and freezing helped revolutionize preservation techniques as they helped 269 store and transport food in an almost fresh state. Since Napoleon's army had bouts of 270 food poisoning during their conquests, he offered a reward for devising a method to 271 help preserve food for a longer duration (Busch, 1997; Jay, 1992). In 1809, Appert 272 succeeded in preserving meats in glass bottles that had been kept in boiling water for 273 varying amounts of time. Thus began the technique of canning which still plays an 274 important role in food storage today. The concept of freezing developed from storage 275 in the Northern parts of the world where ice from frozen lakes was stored for use later 276 in the year (Hueston \& McLeod, 2012). Initially, slow freezing was carried out and this 277 changed the texture and taste of food. Flash freezing was then discovered and this 278 helped store food without changing its texture, colour or taste (Busch, 1997). The first 279 refrigerated ship was the SS Dunedin in 1882 and it revolutionized the meat and dairy 280 industries in Australia and New Zealand (Hueston \& McLeod, 2012). Advances were 281 also made in plant and animal disease control; pigs were moved indoors to decrease 282 disease exposure and to enhance efficiency. 
283 Food safety embraces all the steps in the food production process (processing, 284 preparation and handling of food) and ensures that it is safe to eat. Poor understanding 285 of the importance of food safety and hygiene has in the past contributed to a number 286 of food poisoning outbreaks and at times, deaths (e.g. 2005 E.coli O157 Outbreak in 287 Wales). Reports and studies carried out on these outbreaks identified a wide range of 288 factors contributing to these accidents. Chief amongst these were the relaxed attitudes 289 towards food safety, lack of adequate training provision and many other such human 290 factors related errors (Pennington, 2003). The 2008 Maple Leaf Foods Listeria 291 outbreak in Canada and the 2011 E.coli O104:H4 outbreak in Europe for example, are 292 often seen as indicative of poor regard for hygiene and safety standards amongst food 293 business operators (European Food Safety Authority, 2011; Jespersen \& Huffman, 294 2014; Manning, 2017). The 2009 Godstone Farm E.coli $O 157$ outbreak is seen as a 295 substantial failure of health protection and the flaws of a complex regulatory structure 296 were identified as a major contributing factor (Griffith et al., 2010). This outbreak 297 resulted in 93 cases, most of which were children. The food safety chain is only as 298 strong as its weakest link and the responsibility lies not only with the producers and 299 processors of food but also the governments and consumers (Griffith, 2006). Table 1 highlights the development of the food law in the UK - the purpose of this table is to highlight that regulations alone are not sufficient to ensure food safety and hygiene. It 302 is important for all the stakeholders involved in the food system to work together to 303 ensure food safety and hygiene.

\section{Complex systems: key concepts}

308 One of the most apt definitions for complex systems with regards to the food system 309 is "A system comprised of a (usually large) number of (usually strongly) interacting 310 entities, processes, or agents, the understanding of which requires the development, 311 or the use of, new scientific tools, nonlinear models, out of equilibrium descriptions 312 and computer simulations" (Rocha, 1999). A complex system contains large number 313 of elements (Cilliers, 1998) and is one in which there are more possibilities than can 
314 be actualised (Luhmann, 1985). A complex system might appear to be pseudo-simple 315 (e.g., a leaf) and a simple system might appear to be pseudo-complex (e.g., a 316 combustion engine); "complexity is not located at a specific, identifiable site in a 317 system" (Cilliers, 1998, p. 2). In his book "When Food Kills: BSE E.coli and Disaster 318 Science" (2003), Pennington argues for the need to adopt a systems approach (with 319 systems thinking) to ensure food safety - he uses the concept of a systems based 320 approach to compare food poisoning outbreaks to the Chernobyl, Piper Alpha and 321 railway accidents in Ireland and Britain (Nayak \& Waterson, 2016).

\subsection{Systems thinking}

323 Systems thinking is a way of seeing and talking about reality as it helps us in 324 understanding systems better. It is hence a perspective that uses unique vocabulary 325 for describing systemic behaviour by using tools that help in visually capturing and 326 communicating about systems (Kim, 1999). Systems thinking differs from the 327 traditional reductionist, analytic view as it does not look for "root causes" (Salmon et 328 al, 2016). A systemic perspective is an important complement to analytics thinking as 329 it explains how a system works, the role humans play in these systems and it lets us 330 function more effectively and proactively (Kim, 1999).

\section{4.1.1. System of systems approach (SoS)}

332 Most complex systems focus on performance optimization, robustness and reliability 333 among an emerging group of heterogeneous systems to achieve their goals. Complex 334 systems have a number of concurrent and distributed constituents/actors in a 335 hierarchical order which on their own, are also complex. There needs to be a 336 synergistic effect between the independent systems to achieve the desired overall 337 system goal (Jamshidi, 2009; Kotov, 1997). System of systems can be defined as a 338 "supersystem comprised of other elements" (Jamshidi, 2009) which work in a 339 cooperative manner and interact with each other to achieve a common goal. This 340 approach focuses on the total-system performance even when there is a change in 341 only one or a few of its parts as certain systemic properties can only be treated 342 adequately form a holistic point of view. A system of systems approach helps to 343 effectively implement and analyse large, complex, independent and heterogeneous 344 systems which either work in or are made to work in a cooperative manner (Ackoff, 345 1971; Jamshidi, 2009). 
346 There is a possibility of the total system not achieving its intended goals even if every 347 part of an imperfectly organised system performs as well as possible relative to its 348 individual objectives (Ackoff, 1971). For example, in the food system, although front349 line employees might meet their targets (production of a certain amount of food per 350 day) and management might meet their targets (generating a certain amount of profit), 351 the food system might not achieve all its intended goals (e.g., providing safe and an 352 adequate amount of food to a diverse range of people across the country/globe). It is 353 important to note that the collective goal of the system and all its components is always 354 the same; however, the components might also have additional targets/goals which 355 would eventually lead to the system achieving its end target. Only if subsystems work 356 coherently, will the system function effectively (Ackoff, 1971). The SoS concept 357 already plays a major role in military and engineering applications, however, it is new 358 to the sociotechnical systems world. The emergence of this concept indicates an 359 increase in the complexity of the sociotechnical environment and foreshadows a major 360 evolutionary shift.

\section{4.2. Characteristics of complex systems}

362 Since the food system is tightly interwoven globally and the pace is increasing 363 continuously, it is important to be system-wise. All complex systems share several 364 defining characteristics. Figure 1 illustrates a framework of the functioning of the food 365 366 system using a human factors approach. Human factors emphasizes interactions between people and their environment contributing to the performance, safety (food 367 and employee in this framework), quality of work life, and the goods and services 368 produced (P. Carayon et al., 2006). This framework has been developed to 369 characterize the many interactions between people and their environment in a concise and coherent manner, and illustrate their influence on performance variability of the various stakeholders of the food system. In the work system framework, people (shop372 floor employees, line managers, engineers, organisational management, or 373 consumers) perform a range of tasks using a variety of tools and technology. All these 374 tasks are carried out within a certain physical environment and under specific 375 organisational conditions (policies, guidelines, and standard operating procedures). 376 All the five components of this work system interact and influence each other. These 377 interactions produce different outcomes such as: (a) variable performance by 378 employees; (b) variable quality of food products; and (c) variable quality of work life. 
379 These outcomes are achieved through the occurrences of multiple processes either 380 carried out by: (a) individual shop-floor employees; (b) production lines/teams; (c) 381 consumers while and after purchasing food products. Since this is a descriptive 382 framework, there is no specific guidance as to the critical elements. Further, there is 383 no detailed discussion of processes, guidance for system redesign and improvement 384 of food safety. This framework is an adaptation of the SEIPS framework from the 385 healthcare industry (P. Carayon et al., 2006).

Figure 1 about here

\subsubsection{Purpose}

390 All complex systems have a purpose. It is this purpose that defines the system as a discrete entity and provides it with integrity to hold it together. It is a property of the entire system and not of its parts (Kim, 1999). For example, the purpose of the food supply system is to provide consumers with food that is safe to consume. This 'purpose' 394 is the property of the entire food supply system and not just of its parts such as the 395 farmers or retailers. In line with the purpose of the system, all complex systems have 396 a history that leads to its constant evolution as well as its present behaviours (Cilliers, 397 1998).

398 4.2.2. Efficient functioning and presence of all parts of the system for the purpose to 399 be achieved

400 A large number of elements are required for a system to be complex, else, even grains 401 of sand on a beach would constitute a complex system. However, the number of 402 elements alone does not determine whether a system is a complex one or not. 403 Complex systems are interwoven globally and have complex interactions (Cilliers, 404 1998; Kirlik, 2011; Vicente \& Christoffersen, 2006). It is not possible to have a few of 405 its components missing. Elements within a system interact dynamically and these 406 interactions could either be physical or involve exchange of information (Cilliers, 1998).

407 There is a critical difference between a collection and a system. A system has complex 408 interactions across various systemic levels whereas a collection has no interactions 
409 (Kim, 1999). Hence, taking a part out of a collection would not affect the nature of the 410 collection, but taking a part out of a system or if a part does not function efficiently 411 enough, it could adversely affect the entire system (Rasmussen, 1997). Since 412 sociotechnical systems are dynamic in nature, an accident would develop over time 413 due to normal efforts of individuals in a system and a normal variation in somebody's 414 behaviour. Such variation could lead to accidents (Rasmussen, 1997). Interactions 415 within a complex system are usually of a fairly short range. Although possible, long 416 range interaction is not practical due to constraints. As the interactions are rich in 417 nature (Cilliers, 1998), they still have a wide-ranging influence on the system and can 418 be covered in a few steps. Therefore, these influences can be enhanced, suppressed 419 and altered in a number of ways. Elements in a systemic level are therefore ignorant 420 of the behaviour of the entire complex system and only respond to information that is 421 available locally. If every element was aware of the behaviour of the entire system, it 422 would no more be a complex system, but a complex element (Bar-Yam, 2012a).

\section{4.2.3. Order of arrangement}

424 Complex systems operate under non-equilibrium conditions and hence require 425 constant flow of energy and information to maintain the organisation of the system in 426 order to ensure its survival. Elements in a complex system interact with each other 427 and thus, have the ability to influence to each other as well as the system (Cilliers, 428 1998). If the parts/elements of a collection can be arranged in any order, then they are 429 only a part of a collection (Kim, 1999; Ottino, 2004a). The order in which the parts of 430 a complex system are arranged affects the performance of the system. From 431 Rasmussen's framework, it can be noted that a complex system often has multiple 432 systemic levels - government, regulatory bodies, local area government, technical and 433 operational management, physical processes and equipment and surroundings 434 (Svedung \& Rasmussen, 2002) and the same applies to the food system as seen in 435 Figures 2 and 3 in the study conducted by Nayak and Waterson (2016). If the factors 436 that make up a food system were to be rearranged, the links between them would be 437 broken and hence would lead to a chaos. Interactions are primarily but not exclusively 438 between neighbouring systemic levels or elements within the same systemic level 439 (Cilliers, 1998).

\section{0 \\ 4.2.4. Communication}


441 Communication, which is the exchange of information and the transmission of 442 meaning, forms the basis of a social system. It permits the input of human energy. The 443 set tasks can only be completed if there is effective communication between people 444 within and between subsystems. Exertion of influence, cooperation, social imitation 445 and leadership are some of the social interactions that are often subsumed under 446 communication (Katz \& Kahn, 1978a). Systems that have a full and free flow of 447 information are considered to be healthy. The power of communication is such that it 448 has the ability to reveal as well as eliminate problems. However, miscommunication 449 can also lead to obscuring and confusing existing problems. Effective communication 450 only occurs when it is a two-way process (Nayak \& Waterson, 2017), i.e., the orator 451 as well as the receiver have performed their function. Complications of effective 452 communication are best seen at play in large organisations where there is lesser 453 opportunity than in small groups to get signals from those down the line as interactions 454 in complex systems occur over smaller ranges (Cilliers, 1998). A similar problem also 455 occurs in bottom-up communication. In global systems, communication is an even 456 bigger problem due to language barriers (e.g., messages often meant to be orders are 457 communicated merely as information).

\subsubsection{Direction of communication flow}

459 In any system, it is quite important to be aware of the direction of information flow, i.e., 460 top-down, horizontal and bottom-up. It is important to have a good combination of all 461 these types of communication as it helps keep the entire system connected (Gilmore, 462 2007). For example, in an organisation, the department chief knows about all the 463 division heads and their respective divisions, whereas, each department chief only 464 knows about his or her own division (Katz \& Kahn, 1978a). Similarly, the department 465 chief will not be aware of the problems and the real-world problems that arise in the 466 lower levels of the hierarchical chain.

\section{4.2.4.1.1. Top-down communication}

468 The direction of this type of communication is from superior to subordinate and is the 469 primary interpersonal relationship within an organisation. This type of communication 470 is so important that it has the ability to determine how individuals identify with the 471 organisation, the individual's job satisfaction and commitment (Long \& Vaughan, 2007). 472 There are 5 types of top-down communication (Katz \& Kahn, 1978a): 
473 1. Job instructions - Specific task directives:

474 This type of communication is given priority in industrial, healthcare and military

475 organisations. Direct orders are communicated from superiors in the form of training 476 session, training manuals and written directives.

477 2. Job rationale - Information produced to help better understand the task at hand and 478 its relation to other tasks:

479 This type of communication is designed to provide employees with a full understanding 480 of the job and its possible links to other jobs within the same subsystem.

481 3. Details on organisational procedures and practices

482 In addition to the job description, employees also have obligations and privileges as a 483 member of the system (e.g., benefits, vacations, sick leave, rewards and sanctions). 484 These details complete the descriptions of the role requirements of the organisational 485 member.

486 4. Feedback - Providing subordinates with performance feedback

487 Top-down feedback though often neglected, is an important aspect of healthy systems. 488 Providing such feedback is a form of motivation for employees. It is also important to 489 note that providing feedback to employees is not the only solution to the breakdown 490 of a complex system. It is often quite tedious to provide individual employees a 491 performance report.

492 5. Indoctrination of system and organisational goals - Inculcating a sense of mission 493 by providing information of an ideological character

494 It is important for an organisation to instil its culture and goals in its employees. 495 Similarly, it is also important for a system to have its own goals and to instil these in 496 all its actors across the subsystems. For example, an employee working on the shop497 floor at a food manufacturing plant who knows why he/she is following certain 498 protocols is more certain to follow those protocols (e.g., hand-washing) and thus, it is 499 much easier for him/her to develop an ideological commitment to the food system. The 500 advantages of giving people fuller information on job understanding are twofold: (1) 501 higher possibility of them carrying out their tasks more efficiently and (2) having an 
502 understanding of their job and its relation to the subsystem would increase their ability

503 to identify with organisational goals.

504 4.2.4.1.2. Horizontal communication

505 This form of communication entails passing of information between people within the 506 same hierarchical level and is one of the most difficult forms of communication.

507 Employees receive instruction from the person immediately above them in the 508 hierarchical order and would hence communicate with associates only for task 509 coordination that are specified by rules. It is important to have the right amount of 510 horizontal communication as too much of it could lead to detraction from maximum 511 efficiency (Katz \& Kahn, 1978a).

$512 \quad$ 4.2.4.1.3. Stability through feedback mechanisms

513 Feedback is the transmission and return of information. This type of communication 514 is usually from subordinates to their superiors and typically focuses on information 515 about the subordinates themselves, their colleagues and either work-related or 516 personal problems. Feedback can also include information about tasks to accomplish 517 or organisational policies and practices (Long \& Vaughan, 2007). This can either be 518 positive (enhancing/stimulating) or negative (detracting/inhibiting). Both of these types 519 of feedback are necessary (Cilliers, 1998; Johnson, 2001b) to help in the continuous 520 development of the system. The importance of feedback is that it informs the system 521 about how it is performing relative to the desired state (Johnson, 2001b; Kim, 1999). 522 Three factors need to be addressed to ensure that a complex system has a proactive 523 closed feedback loop: (1) identification of the decision-makers and actors involved in 524 the control of productive processes; (2) definition of the work-space under their control; 525 and (3) defined structure of the distributed control system (Rasmussen \& Svedung, 526 2000).

527 4.2.5. Holism

528 An organisation is a subsystem of one or more larger systems (Katz \& Kahn, 1978b). 529 The concept of holism involves putting the whole before its parts. Therefore, it does 530 not involve breaking an organisation into parts and addressing local issues, but 531 involves looking at the bigger picture, i.e., the entire system/organisation. In the 532 modern world, food business operators and employees face increasing complexity, 
533 change and diversity (Bertalanffy, 1995; Jackson, 2006). Personnel higher up the

534 hierarchical level are expected to manage and provide solutions to problems and 535 issues that might arise in the level(s) whose functioning they overlook. Sometimes, the 536 solutions that they offer and the support provided to them rarely seem to work. Often, 537 these solutions that are offered are termed as 'simple solutions' (Jackson, 2006). The 538 error in this approach lies in the desire to search for simple solutions that address the 539 specific problem and not the other linked factors that either led to that particular 540 problem or to new problems that could arise from this issue. This is often the result of 541 either ignoring or not being aware of interacting factors. Therefore, holism and a 542 practical approach are required to help personnel address complex problem situations' 543 (Jackson, 2006).

544 Although a system consists of multiple subordinate systems, summing up the 545 behaviour of the whole from the isolated parts is not a reliable method. Interactions 546 between the various subordinated systems and the systems which are super547 ordinated to them need to be taken into account to understand the behaviour of the 548 parts (Bertalanffy, 1995). While studying a system, it is important to investigate the 549 position of the various subsystems in the community and in the system as a whole 550 prior. Adopting a holistic approach would help all businesses address broad, strategic 551 and systemic issues as well as narrow, technical ones (Katz \& Kahn, 1978b).

\section{4.2.6. Emergence}

553 "Emergence refers to the relationship between the details and the larger view" (Bar554 Yam, 2012, p. 4). All natural systems are complex adaptive systems (Gunderson \& 555 Holling, 2002). Interactions in complex systems occur in randomised directions (Bar556 Yam, 2004; Morowitz, 2002), i.e., they are not specifically either top-down, horizontal 557 or bottom-up (Katz \& Kahn, 1978a). From these interactions, patterns emerge and 558 these patterns define the behaviour of the components/agents within the system and 559 the behaviour of the whole system. Emergent behaviour relies on the concept of actors 560 in the lower-level of the sociotechnical system leading to higher-level sophistication. 561 Systems are not considered to be emergent if local interactions do not lead to any 562 discernible behaviour higher up the hierarchical chain (Johnson, 2001a). The 563 emergent property of complex systems makes them self-organizing and adaptive 
564 (Ottino, 2004b). This property also enables a system to possess social organisation

565 without the need for constant direction from actors higher up the hierarchical chain.

\section{4.2.7. Interdependence}

567 Interdependence is defined as "the existence of relationships between the behaviour 568 of parts of a system" (Bar-Yam, 2012, p. 2). Complex systems are open systems 569 whose parts are related to its whole and to its environment. This nature of complex 570 systems is called interdependence as all the subsystems affect and are affected by 571 each other. The 'interdependence' property of a complex system has a link with the 572 'communication' property as the latter leads to the former. The impact of 573 interdependence is such that it has a bearing on the entire organisation (Bar-Yam, 574 2012; Goldhaber, 1990). For example, a line manager of a biscuit manufacturing plant 575 taking a decision that work can continue despite there being a broken oven, resulting 576 in under-baked biscuits, could have ramifications throughout the organisation such as 577 significant economic impacts, unhappy superiors and subordinates losing faith in their 578 superiors or loss of jobs. However, if used wisely, this property could also bear fruit. 579 For example, effective and regular communication throughout the food system would 580 not only keep the actors at the top of the hierarchical chain well informed, but would 581 also keep the subordinates satisfied and happy, leading to a positive food safety 582 culture and a reduction in the number of food poisoning related outbreaks.

\section{4.2.8. The law of requisite variety}

584 For a system to achieve maximum stability, the number of states of its control 585 mechanism must be greater than or equal to the number of states in the system that 586 is being controlled. A complex system with good stability only has the ability to adapt 587 to a certain number of stimuli (Ottino, 2004b) - Ashby's law of requisite variety states 588 that 'only variety can destroy variety' (Ashby, 1999, p. 207). A system would only be 589 able to survive as long as the range of responses it marshals (while adapting to the 590 tensions imposed on it) successfully matches the range of situations (threats and 591 opportunities) confronting it. When living systems are involved in such complex 592 systems, behavioural responses are also included. Therefore, responses in complex 593 systems are dependent on the type of stimuli provided and are a combination of 594 behaviour and cognition. Responses of complex systems also vary based on their 595 environments (Boisot \& McKelvey, 2011a). 
596 Most complex systems respond to representations of their environment and not to the 597 actual environment (Boisot \& McKelvey, 2011b). These representations of 598 environments are complex schemas (Gell-Mann, 2002), i.e., they are structured 599 descriptions of an objective external world that neither have too few or too many 600 degrees of freedom. It is important that a system builds schemas in ways that 601 distinguish meaningful information from meaningless stimuli. What constitutes 602 information or noise is defined by the system's expectations and judgements about 603 what is important (Boisot \& McKelvey, 2011b; Gell-Mann, 2002). The characteristics 604 of a complex system are summarized in Table 2.

605

606

Table 2 about here

607

608 5. Applying a complex systems perspective to food safety

609 In order to understand food systems and their food safety cultures better, they need 610 to be analysed from two perspectives: (1) 'micro-perspective' and (2) 'macro611 perspective'. Factors within the micro-perspective influence the functioning and 612 behaviours of national level food systems. Whereas, factors within the macro613 perspective influence the functioning and behaviours of the global food system. The 614 food system is a complex sociotechnical system from both the perspectives (macro 615 and micro) - and hence, needs to be analysed and understood in detail to address 616 negative food safety cultures.

617 5.1. Micro (national) perspective

618 The micro-perspective helps to understand the food system within a country. When 619 seen from this perspective, a range of factors and stakeholders play a key role in 620 providing food safe for consumption (Pennington, 2003), which is the one of the 621 purposes of the food system at the micro-level. As a system of system, the food system 622 encompasses a wide range of processes - from manufacturing of raw materials to 623 consumption of the finished food product by consumers. All these processes have 624 food safety cultures of their own and being a complex system, influence the quality of 625 food available for consumers and food safety. Thus, the complexity of the food system 
626 influences the food safety. At the micro-level, food system globally consists of the

627 following systemic levels: (1) national government and regulatory bodies; (2)

628 organisational management (upper-middle-lower); and (3) front-line actors (shop floor

629 staff and the physical work place). Apart from this, there is also an additional level that

630 plays an active role in national food safety culture - the 'external level'; this consists

631 of societal factors such as market forces, media and societal values and priorities,

632 historic events and global politics (Nayak \& Waterson, 2016; Rasmussen, 1997). Table

6333 highlights the components of the food system across various systemic levels in the

634 UK and the US, and the roles they currently play. It also highlights similarities in the

635 structures of food systems at the national level across two major economic

636 superpowers. Finally, Table 3 brings to light all the activities and resources that go into

637 production, distribution and consumption; the drivers and outcomes of these

638 processes; and the complex extensive relationships between the system participants

639 and components (Neff \& Lawrence, 2014).

640

641

Table 3 about here

642

643 Every country has a mix of large-scale food businesses as well as medium, small and 644 micro-scale food businesses. Although disregard for hygiene practices is usually 645 attributed to individuals, it is often related to the prevailing organisational culture 646 (Clayton \& Griffith, 2008; Griffith et. al., 2010). A high level of trust within as well as 647 between organisational levels as well as systemic levels is important to have a positive 648 food safety culture. One of the factors that leads to development of trust and 649 understanding in the food system at the micro-level is open and free flow of information 650 across the system (Pennington, 2003), without which, there is an increased risk of 651 food poisoning outbreaks (Nayak \& Waterson, 2016; Pennington, 2009; Pennington, 652 1997). Behaviours at the lower-levels of the sociotechnical system lead to emergence 653 in higher level sophistication. This is also true vice-versa as this is one of the factors 654 that define employees' job satisfaction. A negligent safety culture affects the 655 behaviours of people across every systemic level in a complex system (Stanwell-Smith, 656 2013). 
658 The best example to highlight the complexity of the current food supply chain is that 659 of a cheeseburger. Researchers at the University of Minnesota mapped the global 660 food supply chain of cheeseburgers produced at a large fast food chain. A 661 cheeseburger contains more than 50 ingredients imported from countries in every 662 continent except the Arctic (Hueston \& McLeod, 2012). Food supplies move all over 663 the world and as a result food-processing supplies move globally. These include 664 processing equipment, packaging and chemicals such as disinfectants and 665 preservatives. Agricultural inputs such as feed, fertilizer, vaccines, pharmaceuticals, 666 harvesting and planting equipment also move worldwide (Hueston \& McLeod, 2012).

667 A single food component (e.g., bread) contains ingredients that have travelled from all 668 parts of the world, and multiple food components make up a food product (e.g., bread, 669 cheese, meat, lettuce, ketchup together make a cheeseburger). Thus, it is imperative 670 to understand and analyse the scale of stakeholders involved and the complexity of 671 the relationships between the system components of the global food system in order 672 to achieve food safety. The food miles (Pirog \& Benjamin, 2003) described above also 673 highlight the need for smooth, efficient and open top-down, bottom-up and horizontal 674 communications for the food system at the macro-level to progress without major 675 glitches.

676 At the macro-level too, the food system is a system of systems - government regulatory 677 systems, private sector initiatives, educational efforts and consumer actions are a part 678 of the food system. Food systems are linked to food safety and contamination can 679 occur at any point in this complex system. There are an increasing number of food 680 safety related controversies at a transnational level (Lien, 2004) due to the scale and 681 complexities of food systems in the modern world (Ercsey-Ravasz et al., 2012). Hence, 682 it is important to have adequate and adaptive prevention and control strategies in place. 683 Global consumers are vulnerable to changes in regulations, shifts in practices and 684 routines that occur in any part of the world (Lien, 2004). The more complex a system 685 gets, higher are the chances for things to go wrong, and the larger the scale of the 686 operation, the more people are likely to get affected. The food system is a particularly 687 high risk industry as consumers range from new born babies to the elderly, and a host 688 of other immunocompromised population (Food Standards Agency, 2012; Jespersen 
689 et al., 2016; Powell et al., 2011; Whaetherill, 2009). Thus, the stakes are high in the 690 event of a food poisoning outbreak.

691 The food industry comprises of various systemic levels (e.g., Board of Directors; upper, 692 middle and lower management; and front-line employees). The structure of the 693 national food system, much like many other systems, adheres to Rasmussen's socio694 technical systems framework (Nayak \& Waterson, 2016). These systemic levels have 695 been referred to as subsystems by authors such as Hueston and McLeod (2012). Due 696 to the short-range complex interactions across and between various systemic levels 697 as highlighted in Nayak and Waterson (2016) and the holistic and interdependent 698 nature of the food system, it is not possible to predict the properties if each systemic 699 level when looked at in isolation. However, if systemic behaviour is understood, it is 700 possible to anticipate behaviour and work with systems rather than being controlled 701 by them (Kim, 1999). Behaviours at the lower levels of the sociotechnical systems also 702 lead to emergent behaviours higher up the hierarchical chain.

703 Hueston and McLeod (2012) state that food systems can be called as adaptive 704 systems as they have no boundaries, i.e., faulty individual actions can affect the entire 705 food system and thus affect food production as well as consumption. However, it is 706 imperative to keep in mind that every system has a boundary of acceptable behaviour 707 (see Figure 2) to which behaviour will migrate to under the presence of strong 708 gradients (Ashby, 1999; Rasmussen, 1997). It is also important to note that complex 709 systems also have a memory (Hueston \& McLeod, 2012; Nayak \& Waterson, 2017) 710 where present behaviour is affected by prior behaviour - hence, past successes as 711 well as failures influence organisational behaviour.

712

713

Figure 2 about here

714

715 However, it is not possible to predict the overall behaviour of the food system based 716 on the behaviour of individual elements (Cilliers, 1998). An example of this is the 2005

717 E.coli 0157 Outbreak in South Wales. Faulty auditing by food inspectors (Government 718 Level) led to lack of regard for hygiene practices at the Organisational level, which in719 turn led to there being no protocol for cleaning leading to inadequate cleaning of 
720 equipment which led to cross-contamination (Nayak \& Waterson, 2016). Another 721 example is the 2012 E.coli 0157 Outbreak in Canada where the inadequate provision 722 of food safety training by the management led to the absence of product recall 723 protocols. This in turn led to widespread confusion and panic when the first few 724 incidents occurred leading to delays and widespread consequences on public health 725 as well as the organisation (Jespersen et al., 2017). These examples highlight the fact 726 that the food system is non-linear, and a small perturbation may or may not have a 727 large effect. However, being a high-risk industry, it would be risky and possibly 728 catastrophic to take this chance, especially on a global scale.

729 Since food systems are dynamic and interdependent, it is not possible to have one 730 system that meets all needs. However, as food systems are complex systems, even 731 a small positive change would positively alter the entire system of systems. A relevant 732 model that illustrates the various factors influencing performance and an effective 733 complex system design is the 'onion model' by Wilson and Sharples (2015). This 734 model applies a holistic approach to understand complex interacting systems and 735 subsystems that involve people. It is important to apply the right approach instead of 736 applying the right type of knowledge (Waterson \& Catchpole, 2015). Table 4 highlights 737 similarities in the gaps across various national food safety systems citing examples 738 from the UK, the US and the European Union (EU). It is necessary to develop a model 739 that would help identify the links between these factors in order to address issues 740 related to global food safety.

741

Table 4 about here

743

744 6. Systems analysis of the global food systems using the STAMP methodology

745 The STAMP (System-Theoretic Accident Model and Processes) accident analysis 746 methodology is underpinned by systems and control theory (Salmon et al., 2016) 747 rather than the traditional reliability theory (Leveson, 2015). Systems theory is an 748 effective method to analyse accidents, particularly system accidents (Leveson, 2004; 749 Rasmussen, 1997). According to Leveson (2004), accidents are either a result of 750 inadequate control or inadequate enforcement of safety-related constraints on the 
751 development, design and operation of the system. “... accidents occur when external 752 disturbances, component failures or dysfunctional interactions among system 753 components are not adequately handled by the control system ..." (Leveson, 2004, p. 754 250). In the food safety context for example, the model might suggest that one of the 755 factors that could lead food poisoning outbreaks is when controls such as mandatory 756 internal Hazard Analysis and Critical Control Points (HACCP) audits are not carried 757 out diligently, thus failing to identify faults, rectify and report them.

758 STAMP views safety as a manageable control related incident if a well-designed 759 control structure is in place. The goal of this control structure must be to enforce 760 constraints on actors within the system. The STAMP method helps analysts identify 761 the existing types of controls in a system/complex system and their failure points 762 (Leveson, 2004; Salmon et al., 2016). A generic structure of a STAMP model is 763 presented in Figure 3 (Leveson, 2004). Most accident and system analysis models 764 define safety management in terms of preventing component failure events; however, 765 STAMP defines safety management as a "continuous control task to impose the 766 constraints necessary to limit system behaviour to safe changes and adaptations" 767 (Leveson, 2004, p. 251). According to this model, accidents are to be understood by 768 identifying controls and analysing the reasons behind these controls not being 769 effective or adequate enough to prevent or detect maladaptive changes and enforce 770 the safety constraints in place. Hence, violated safety constraints also need to be 771 identified. Constraints, control loops, process models and levels of control are the 772 basic concepts in STAMP (Leveson, 2004).

773

774

Figure 3 about here

775

776 6.1. Basic concepts of STAMP

777 6.1.1. Role of constraints

778 Mariam-Webster dictionary (2017) defines constraints as a limitation or a restriction of 779 performance of a specific action. Control is always associated with constraints, 780 especially in systems theory. Instead of viewing accidents as the end result of a series 
781 of events, in the STAMP model, it is viewed as the result of a lack of constraints

782 imposed on the system design and on operations across the various socio-technical

783 levels. In systems theory, safety is viewed as an emergent property that arises when

784 the components of a system interact effectively within an environment. These

785 emergent properties are controlled and enforced by a set of constraints (control laws).

786 Accidents occur due to a lack of appropriate constraints on the interactions (Leveson,

787 2004).

788 As an example, one of the unsafe behaviours in the 2011 listeriosis in Colorado, USA 789 was the failure to use the correct equipment. The farm management team was legally 790 obliged to audit employee work practices and provide them with regular training. The 791 farm was also obliged to comply with regulations enforced by the US Food and Drug 792 Administration (U.S. Food and Drug Administration, 2011). However, poorly designed 793 food safety regulations and a significant delay in implementing the Food Safety 794 Modernization Act led to an inadequate enforcement of constraints such as regular 795 food safety inspections and facility design requirements. Similarly, several questions 796 need to be answered to further establish why the employees used incorrect equipment 797 - why was there a delay in implementing the new Act?; did the government not 798 consider the implications of delaying the "implementation" phase of the new Act?; was 799 the farm management not knowledgeable enough to understand the risks (health as 800 well as financial) associated with disregard for hygiene and cleanliness in a food 801 business, and not providing adequate information and guidance to employees? Such 802 an approach allows one to reconsider the complexity of the food system such as the 803 politicizing food safety regulations, the working structure of food safety regulatory 804 bodies and the impact each they have on national/transnational food safety and food 805 business policies and practices. It is important to identify all the constraints prior to 806 designing the safety process in the system; these constraints also include social and 807 organisational aspects of the system.

\section{6.1.2. Control loops and process models}

809 In systems theory, open systems are defined as interrelated components that are kept 810 in a state of dynamic equilibrium through feedback loops of information and control. 811 Complex systems are constituted by intricate sets of non-linear relationships and 812 feedback loops which lead to whole system analysis becoming extremely complicated 
813 (Cilliers, 1998; Leveson, 2004; Ottino, 2004b) unless there is a suitable model to do 814 so. Only if a system's overall performance is controlled will it be able to produce the 815 desired outcome while satisfying safety and quality constraints (Leveson, 2004). To 816 possess control over a system, four conditions need to be met (Ashby, 1999): (1) the 817 controller must have goals and objectives; (2) the controller must be able to affect the 818 state of the system; (3) the controller must be or contain a model of the system; and 819 (4) the controller must be able to ascertain the state of the system.

820 Controllers working within the system must have a mental model of the level of the 821 hierarchical system of which they are a part and the relationships among system 822 variables, the current state of the system variables and ways in which the process can 823 change state. This helps controllers determine the control actions required and these 824 are communicated back in the form of feedback. Accidents can occur if controllers 825 form inaccuracies in the mental model (Leveson, 2004). In the 1996 E.coli 0157 826 outbreak in Scotland employees working at the organisational level had no idea about 827 who to report to in the event of disturbances in the food processing process. Also, as 828 there were no documented systems in place, they were unaware of the current 829 condition of the system variables. Most of the employees were not trained to handle 830 food and hence they had no idea about how the process could change state (Nayak $831 \&$ Waterson, 2016). These were few of the major factors that led to the outbreak. If the 832 entire food system is looked at, there are multiple human as well as automated 833 controllers; however, the number of human controllers is greater in the food system.

834 6.1.3. Socio-technical levels of control

835 In systems theory, systems are viewed as hierarchical structures with systemic levels 836 where each of these levels impose constraints on the activity in the level beneath it 837 (Checkland, 1981; Leveson, 2004). There is also a possibility of there being 838 constraints across one systemic level and this needs to be further investigated, 839 especially in the food system. Constraints are required on the relationships between 840 the values of system variables; such constraints are known as control laws. Safety841 related control laws specify those relationships between system variables that would 842 lead to non-hazardous system states (Leveson, 2004), for example, while handling 843 raw meat, employees on the factory floor must wear a different set of uniform. Safe 
844 changes and adaptations in a complex system will only be assured if control processes 845 enforce such constraints.

846 It is quite important that constraints on behaviour are reflected in the company policy 847 and standards. There has been a change in the style of management from 848 management by oversight to management by insight (Leveson, 2004). This has been 849 a positive change as there are now greater levels of feedback control exerted over the 850 lower levels and a change from prescriptive management control to management by 851 objectives. The objectives are interpreted and satisfied according to the local context 852 (Leveson, 2004; Rasmussen, 1997). Management are now delegating decisions to 853 various employees across the lower levels of hierarchy. This requires an explicit 854 formulation of the value criteria to be used and effectively communicating the values 855 down the systemic levels. Although generic instructions and guidance are required 856 from the level above in order to avoid accidents, execution of the guidance can be left 857 to lower levels (Leveson, 2004).

858 6.2. Understanding flaws in the control structures that lead to outbreaks

859 Section 6 mentioned that accidents were caused by inadequate control where the 860 control loop creates dysfunctional interactions in the process. Hence, by 861 understanding the flaws in the control structures (development and operations), the 862 process that leads to accidents can be understood (Leveson, 2004). These flaws have 863 been classified by Leveson (2004) to make it easier to identify the factors involved in 864 an accident during accident analysis or while designing models to prevent accidents.

865 There are multiple control loops within a complex system and each control loop can 866 contribute to inadequate control. At any point in a control loop where humans or 867 organisations are involved, the context in which decision are made may vary and 868 hence need to be evaluated in order to analyse the behaviour shaping mechanisms. 869 This helps in understanding how and why unsafe decisions were made (Leveson, 870 2004). Accidents may also occur due to basic component failures such as inadequate 871 constraints on the process; inadequate and faulty designs; lack of feedback and 872 correspondence between individual component capacity (including humans) and task 873 requirements; environmental disturbances; inadequate maintenance; and physical 874 degradation (of machines or the entire system) over time (Leveson, 2004). In order to 875 avoid component failure, it is important to make the components resistant to internal 
876 and external influences that are detrimental to the system dynamics. Although 877 management by insight is a better approach, there must be safety margins within 878 which a system should operate. Another method to avoid component failure is by 879 having operational controls in order to ensure that the component operates within its 880 designed environment and through periodic, effective and thorough inspections. The 881 STAMP model helps identify the reasons behind component failures (Leveson, 2004) 882 and this could be very helpful as it would help prevent future whole system failures.

883 Figure 4 illustrates an example of a STAMP model of the UK food system. This model 884 was developed based on information gathered from various sources such as 885 government documents (e.g., Miller, 2014), stakeholder websites (e.g., Food 886 Standards Agency and the UK government websites) and academic literature (Nayak 887 \& Waterson, 2016; Pennington, 2003). One of the researchers constructed a draft 888 version of the UK food system as seen in Table 3 in Section 5.1. Following this, a 889 STAMP model was constructed to fit the UK food system. Actors who resided at each 890 of the control structure levels were identified and the control and feedback loops 891 existing between different control structure levels were mapped. The model was 892 reviewed by the other researcher who is experienced in constructing STAMP models.

893 Using system theory to model complex organisations involves dividing the entire 894 complex system into various hierarchical systemic levels (Leveson, 2004; Rasmussen, 895 1997). Figure 2 (in this article), as well as multiple Accimap analyses of global food 896 poisoning outbreaks (Nayak, 2018) highlight that food systems across the world have 897 multiple hierarchical complex socio-technical systemic levels. As seen from Figure 6, 898 the STAMP model can also be applied to a food system. The advantage of this model 899 over the model designed by Rasmussen and Svedung in 2000 (Rasmussen \& 900 Svedung, 2000) is that the former divides the development and operations stages, 901 therefore giving a more detailed analysis. As seen in Figure 4, there are two 902 hierarchical control structures: (1) system development on the left and (2) system 903 operation on the right with interactions between them. A food manufacturer, for 904 example, would only have development under its immediate control, however, safety 905 involves development (growing, manufacturing, processing, packaging and 906 inspections and regulations related to these) as well as operations (import, export, 907 transport and inspections and regulations related to these) of food manufacturing. 
908 Figure 4 establishes that although the links between various systemic levels can be 909 established using existing documents, further studies need to be carried out to further 910 elaborate on and analyse the control and feedback structures of the food system 911 across the world. The outcomes of such a study would help identify and address 912 potential and existing flaws in the control and feedback structures of food systems at 913 a global scale, learn from well-designed and well-structured food systems and develop 914 proactive and systemic-level interventions to improve global food safety.

Figure 4 about here

\section{7. Conclusions, limitations and future work}

919 Global interconnected food systems play a major role in the modern society to harness 920 a multiplicity of complex supply chains. Globalisation of food networks has introduced 921 an unprecedented level of complexity to the global food system; this has not only 922 brought significant benefits, but also systemic risks. Due to the interconnectivity across 923 systemic levels, disruptions at one point in the system would lead to reverberations in 924 the form of economic, social and political impacts throughout the entire system 925 (Maynard, 2015). Hence, understanding the entire food system is the need of the hour 926 to enhance global resilience to systemic food system failures. Globalisation of the food 927 system initiated a change in the food safety domain. New techniques were and are 928 still being developed to further the reach of the food system globally.

929 As seen in above sections, the characteristics of the global food system resonate with 930 the characteristics of complex systems. Therefore, it is necessary to use systems 931 analysis methods to understand the interactions between the components of the food 932 system. With the use of STAMP, leading indicators can be identified (Leveson, 2015) 933 and this would help identify the potential for a food poisoning outbreak before it occurs.

934 STAMP can be used to identify food system specific leading indicators which would 935 then help in designing appropriate and specific models. Similar to accidents in other 936 high-risk industries, food poisoning outbreaks also have warning signs before they 937 occur. Before an outbreak occurs, 'weak signals' are only viewed as noise (Leveson, 938 2015). 
939 Systems analysis models such as STAMP have the ability to tackle limitations of event 940 chain models. It not only has the ability to address single component failures but also 941 can analyse interactions among various components in the complex food system 942 (Leveson, 2004). Such models also adopt a whole system approach where they 943 consider the entire safety control structure to determine reasons behind inefficiencies 944 of existing constraints on safe behaviour. It is quite difficult to analyse the performance 945 of complex systems, especially when looking at the 'whole system' (Cilliers, 1998; 946 Leveson, 2004). Currently, individual components are analysed and any inadequacies 947 are addressed accordingly. Safety metrics could be identified by the use of system 948 accident models and basic concepts of safety constraints. Determining adequacy of 949 control over constraints, evaluating potential design errors, assessing the 950 organisational structure and human behaviour leading to hazards, detecting errors in 951 the developmental and operational environments and identifying maladaptive changes 952 over time (Leveson, 2004) could be few of the causal factors that could be identified 953 and analysed using this model.

954 One of the limitations of STAMP is that it does not specify an accident investigation 955 process. Since variations exist among investigation reports, if food outbreaks alone 956 are used to develop a control process model, the model might be biased towards the 957 report used to analyse accidents and outbreaks (Stoop \& Benner, 2015). Identifying 958 all stakeholders relevant to the food system and conducting interviews and focus 959 group discussions with them, in addition to analysing outbreak reports, would help 960 tackle this limitation. This would permit gathering all the possible perspectives and 961 factors that play a role in providing food safe for consumption at the micro and macro962 levels in the food system. It is important to note that it is not possible to use a single 963 systems analysis method in isolation to help identify key insights for interventions, and 964 hence, there is a need to develop new methods or further adapt existing methods to 965 understand dynamic adaptive systems (Thatcher et al., 2019).

966 Figure 4 illustrates the influence of external factors (macro-environment) on the micro967 environment of food businesses. Regulatory bodies, national policies and politics 968 impact the performance of the food industry as the former play a critical role in drafting 969 and enforcing all food-related regulations (such as safety, production, import and 970 export). Any anticipated change in regulations leads to confusion and panic among 971 stakeholders - such uncertainty often sets the food system up to fail. An example of 
972 the influence of uncertainty on food businesses and food safety due to external factors 973 has been highlighted in Section 6.1.1. The delay in implementing the new regulations 974 in the US led to confusion and panic, eventually leading to a food poisoning outbreak.

975 This past event should serve as an important learning point as there exists a risk of a 976 similar such occurrence during and after Brexit - at the time of writing this article, it is 977 a well-known fact that the UK is struggling to reach a deal with the European Union 978 (EU) regarding trade policies after the UK leaves the EU in 2019. This uncertainty has 979 already led to the media speculating possible food safety risks and the dangers to 980 consumer and stakeholder safety should the UK government not be successful in 981 reaching a favourable trade agreement with the EU (Rees-Mogg, 2018; Rayner, 2017, 982 2018). Hence, it is the need of the hour to further investigate methods of reducing 983 negative external influences on the food system.

984 While every country across the world has its own prescribed food safety system, a 985 vast majority of them engage extensively in the export and import of food products. 986 This results in food systems being composed of interrelated subsystems, each with its 987 own hierarchical structure, all of which lead to the lowest level within an elementary 988 subsystem (Simon, 1962; Thatcher et al., 2019). Further evidence across multiple 989 disciplines characterise these multiple interacting systems in the form of nested 990 hierarchies with smaller, less complex systems embedded within larger, more complex 991 systems (Carayon et al., 2015; Clegg et al., 2017; Gunderson \& Holling, 2002; 992 Thatcher et al., 2019; Thatcher \& Yeow, 2016). Larger systems provide the broader 993 framework which helps understand smaller systems, while smaller systems provide 994 the functional elements that enable larger systems achieve stability and function in a 995 specific manner.

996 As food travels long distances in the modern world, a global model is required to help 997 identify factors that occur at any point in the global food system. Conducting the above998 mentioned process at a global scale would help develop a "prototypical food system" 999 model - this would provide a global benchmark and a backbone structure upon which 1000 country-specific food systems could be designed. Being able to look at the whole 1001 picture, identify emerging control/constraint failures and learn from high performing 1002 food system models would not only benefit all the stakeholders of the global food 1003 industry, but also protect consumers from food poisoning related ill health and deaths. 
1004 Therefore, it is the need of the hour to adopt a proactive approach and study food 1005 systems at micro and macro-levels globally and the interactions between various 1006 factors within and between food systems. This would help in the development of a truly 1007 global model that would have the ability to identify food safety related issues across 1008 the food system. 


\section{References}

1010

1011

1012

1013

1014

1015

1016

1017

1018

1019

1020

1021

1022

1023

1024

1025

1026

1027

1028

1029

1030

1031

1032

1033

1034

1035

1036

1037

1038

1039

1040

1041

1042

1043

1044

1045

1046

1047

1048

Ackoff, R. L. (1971). Towards a system of systems concepts. Management Science, 17(11), 661-671.

Adam Bros. Farming, I. (2018). ADAM BROS. FARMING, INC. RECALLS RED AND GREEN LEAF LETTUCE AND CAULIFLOWER BECAUSE OF POSSIBLE HEALTH RISK. Retrieved from http://e-journal.uajy.ac.id/14649/1/JURNAL.pdf

Ashby, W. (1999a). An Introduction to Cybernetics (2nd ed.). London: Chapman \& Hall Ltd. https://doi.org/10.2307/3006723

Ashby, W. (1999b). An Introduction to Cybernetics (2nd ed.). London: Chapman \& Hall Ltd. https://doi.org/10.2307/3006723

Bar-Yam, Y. (2004). A Mathematical Theory of Strong Emergence Using Multiscale Variety. Complexity, 9(6), 15-24. Retrieved from https://s3.amazonaws.com/objects.readcube.com/articles/downloaded/wiley/9b8 1125b9ac7465b31b6e2e9f0874130cab6444ebf8176ec401bb7760fac386c.pdf? X-Amz-Algorithm=AWS4-HMAC-SHA256\&X-AmzCredential=AKIAIS5LBPCM5JPOCDGQ\%2F20170407\%2Fus-east1\%2Fs3\%2Faws4_request\&

Bar-Yam, Y. (2012a). Introducing Complex Systems. Heterocycles, 85(7), 1-56. Retrieved from http://citeseerx.ist.psu.edu/viewdoc/download?doi=10.1.1.372.1791\&rep=rep1\&t ype=pdf

Bar-Yam, Y. (2012b). Introducing Complex Systems. Heterocycles, 85(7), 1-56.

Bertalanffy, L. von. (1995). Some System Concepts in Elementary Mathematical consideration. In General System Theory (12th ed., pp. 66-74). New York: George Braziller.

Boisot, M., \& McKelvey, B. (2011a). Complexity and Organization-Environment Relations: Revisiting Ashby's Law of Requisite Variety. In P. Allen, S. Maguire, \& B. McKelvey (Eds.), The SAGE Handbook of Complexity and Management (1st ed.). London. Retrieved from http://pespmc1.vub.ac.be/books/IntroCyb.pdf

Boisot, M., \& McKelvey, B. (2011b). Complexity and Organization-Environment Relations: Revisiting Ashby's Law of Requisite Variety. In P. Allen, S. Maguire, \& B. McKelvey (Eds.), The SAGE Handbook of Complexity and Management (1st ed.). London.

Busch, L. (1997). Grades and standards in the social construction of safe food. In The Social Construction of Safe Food. Trondheim.

Busch, L. (2004). Grades and Standards in the Social Construction of Safe Food. In M. Lien \& B. Nerlich (Eds.), The Politics of Food (1st ed., pp. 163-178). Oxford: BERG.

Carayon, P., Hancock, P., Leveson, N., Noy, I., Sznelwar, L., \& van Hootegem, G. (2015). Advancing a sociotechnical systems approach to workplace safety - 
developing the conceptual framework. Ergonomics, 58(4), 548-564.

1050

1051

1052

1053

1054

1055

1056

1057

1058

1059

1060

1061

1062

1063

1064

1065

1066

1067

1068

1069

1070

1071

1072

1073

1074

1075

1076

1077

1078

1079

1080

1081

1082

1083

1084

1085

1086

1087

1088

1089

Carayon, P., Schoofs Hundt, A., Karsh, B. T., Gurses, A. P., Alvarado, C. J., Smith, M., \& Brennan, P. F. (2006). Work system design for patient safety: The SEIPS model. Quality and Safety in Health Care, 15, 50-58. Retrieved from https://qualitysafety.bmj.com/content/qhc/15/suppl_1/i50.full.pdf

Cassano-Piche, A., Vicente, K. J., \& Jamieson, G. A. (2006). A Sociotechnical Systems Analysis of the BSE Epidemic in the UK through Case Study. In Proceedings of the Human Factors and Ergonomics Society Annual Meeting (Vol. 50, pp. 386-390). https://doi.org/10.1177/154193120605000337

Centers for Disease Control and Prevention. (2019). Outbreak of E. coli Infections Linked to Romaine Lettuce. Retrieved March 25, 2019, from https://www.cdc.gov/ecoli/2018/o157h7-11-18/index.html

Checkland, P. (1981). Systems Thinking, Systems Practice. New York: John Wiley \& Sons, Inc.

Cilliers, P. (1998). Complexity and Postmodernism: Understanding Complex Systems (3rd ed.). Oxon: Routledge.

Clayton, D. A., \& Griffith, C. J. (2008). Efficacy of an extended theory of planned behaviour model for predicting caterers' hand hygiene practices. International Journal of Environmental Health Research, 18(2), 83-98.

Clegg, C. W., Robinson, M. A., Davis, M. C., Bolton, L. E., Pieniazek, R. L., \& McKay, A. (2017). Applying organizational psychology as a design science: A method for predicting malfunctions in socio-technical systems (PreMiSTS). Design Science, 3(May), 1-31. https://doi.org/10.1017/dsj.2017.4

Ercsey-Ravasz, M., Toroczkai, Z., Lakner, Z., \& Baranyi, J. (2012). Complexity of the international agro-food trade network and its impact on food safety. PLOS ONE, 7(5), 1-7. https://doi.org/10.1371/journal.pone.0037810

European Food Safety Authority. (2011). Shiga toxin-producing E. coli (STEC) O104:H4 2011 outbreaks in Europe: Taking Stock. EFSA Journal (Vol. 9). Retrieved from http://www.ncbi.nlm.nih.gov/pubmed/22347544\%5Cnhttp://www.pubmedcentral. nih.gov/articlerender.fcgi?artid=PMC3279763

Fang, X., Huang, H., \& Leung, P. S. (2018). Competitiveness of local food: An empirical analysis of the tomato market dynamics. International Food and Agribusiness Management Review, 21(1), 89-100. Retrieved from http://www.euro.who.int/_data/assets/pdf_file/0009/144981/EHEC_outbreak_1 0_June_2011.pdf

FAO, WFP, \& IFAD. (2012). The State of Food Insecurity in the World 2012. Economic growth is necessary but not sufficient to accelerate reduction of hunger. FAO. Rome. https://doi.org/ISBN 978-92-5-107316-2

Food and Drug Administration. Standards for the Growing, Harvesting, Packing, and Holding of Produce for Human Consumption, Pub. L. No. 0910-AG35, 80 
1090

1091

1092

1093

1094

1095

1096

1097

1098

1099

1100

1101

1102

1103

1104

1105

1106

1107

1108

1109

1110

1111

1112

1113

1114

1115

1116

1117

1118

1119

1120

1121

1122

1123

1124

1125

1126

1127

1128

1129

Federal Register 74353 (2015). United States of America: U.S. Department of Health \& Human Services. https://doi.org/10.1007/s13398-014-0173-7.2

Food Standards Agency. (2005). General Guidance for Food Business Operators on Microbiological Criteria for Foodstuffs. Food Standards Agency. Retrieved from http://www.foodlaw.rdg.ac.uk/pdf/uk-06001-micro-criteria.pdf.

Food Standards Agency. Food Law [Code of Practice (England)] (2012).

Gell-Mann, M. (2002). What is complexity? In A. Curzio \& M. Fortis (Eds.), Complexity and Industrial Clusters (pp. 13-24). Germany: Physica-Verlag.

Giedion, S. (1948). Mechanization takes command: a contribution to anonymous history. New York: Oxford University Press.

Gilmore, D. (2007). Leadership and Supervision. In Encyclopedia of Industrial and Organizational Psychology (pp. 443-445). SAGE Publications, Inc.

Goldhaber, G. M. (1990). What is organizational communication? In Organizational communication (5th ed., pp. 4-29). Wm.C.Brown Publishers.

Griffin, G. (2010). Review of the major outbreak of E. coli 0157 in Surrey, 2009. Retrieved from http://www.griffininvestigation.org.uk/report/full_report.pdf

Griffith, C. J. (2006). Food safety: where from and where to? British Food Journal, 108(1), 6-15. https://doi.org/10.1108/00070700610637599

Griffith, C. J., Jackson, L. M., \& Lues, R. (2017). The food safety culture in a large South African food service complex: Perspectives on a case study. British Food Journal, 119(4), 729-743. Retrieved from https://www.scopus.com/inward/record.uri?eid=2-s2.085015945727\&doi=10.1108\%2FBFJ-11-20160533\&partner $\mid \mathrm{D}=40 \& \mathrm{md} 5=\mathrm{e} 6 \mathrm{f} 67 \mathrm{c} 7668988 \mathrm{~b} 4 \mathrm{~b} 3654 \mathrm{e} 6858 \mathrm{c} 29 \mathrm{bbdf}$

Griffith, C. J., Livesey, K. M., \& Clayton, D. (2010). The assessment of food safety culture. British Food Journal, 112(4), 439-456. https://doi.org/10.1108/00070701011034448

Gunderson, L., \& Holling, C. (2002). Panarchy: Understanding Transformations in Human and Natural Systems (1st ed.). Washington DC: Island Press. Retrieved from https://linkinghub.elsevier.com/retrieve/pii/S0921800904000357

Hollnagel, E. (2009). The ETTO principle: efficiency-thoroughness trade-off: why things that go right sometimes go wrong. Ashgate. Farnham: Chapman and Hall/CRC.

Hueston, W., \& McLeod, A. (2012). Overview of the Global Food System: Changes over Time/Space and Lessons for Future Food Safety. In E. Choffnes, D. Relman, L. Olsen, R. Hutton, \& A. Mack (Eds.), Overview of the Global Food System: Changes over Time/Space and Lessons for Future Food Safety (pp. 189-197). Washington DC: The National Academic Press. https://doi.org/10.17226/13423

Inglis, D. (2016). Globalization and food: The dialects of globality and locality. In B. 
1152

1153

1154

1155

1156

1157

1158

1159

1160

1161

1162

1163

1164

1165

1166

1167 1168

Turner \& R. . Holton (Eds.), Handbook of Globalization Studies (2nd ed., pp. 469-490). Abingdon: Routledge.

Jackson, M. C. (2006). Creative holism: A critical systems approach to complex problem situations. In Systems Research and Behavioral Science. https://doi.org/10.1002/sres.799

Jamshidi, M. (2009). Introduction to system of systems. In M. Jamshidi (Ed.), System of systems engineering: Innovations for the 21st century (pp. 1-20). New Jersey: John Wiley \& Sons, Inc.

Jay, J. M. (1992). Modern Food Microbiology. New York: Van Nostrand.

Jespersen, L., Griffiths, M., Maclaurin, T., Chapman, B., \& Wallace, C. A. (2016). Measurement of food safety culture using survey and maturity profiling tools. Food Control, 66, 174-182. https://doi.org/10.1016/j.foodcont.2016.01.030

Jespersen, L., \& Huffman, R. (2014). Building food safety into the company culture: a look at Maple Leaf Foods. Perspectives in Public Health, 134(4), 200-205. https://doi.org/10.1177/1757913914532620

Jespersen, L., MacLaurin, T., \& Vlerick, P. (2017). Development and validation of a scale to capture social desirability in food safety culture. Food Control, 82, 4247. https://doi.org/10.1016/j.foodcont.2017.06.010

Johnson, S. (2001a). Introduction. In Emergence (pp. 11-23). New York: Penguin Group.

Johnson, S. (2001b). Listening to Feedback. In Emergence (pp. 130-162). New York: Penguin Group.

Katz, D., \& Kahn, R. (1978a). Communication, Feedback Processes and Evaluation. In The Social Psychology of Organizations (2nd ed., pp. 427-473). New York: John Wiley \& Sons, Inc.

Katz, D., \& Kahn, R. (1978b). Defining Characteristics of Social Organizations. In The Social Psychology of Organizations (2nd ed., pp. 35-68). New York: John Wiley \& Sons.

Kim, D. H. (1999). Introduction to Systems Thinking. (K. O'Reilly \& L. Johnson, Eds.). Pegasus Communications, Inc. Retrieved from http://www.thinking.net/Systems_Thinking/Intro_to_ST/intro_to_st.html

Kirezieva, K., Luning, P., Jacxsens, L., Allende, A., Johannessen, G., Tondo, E., ... van Boekel, M. (2015). Factors affecting the status of food safety management systems in the global fresh produce chain. Food Control, 52, 85-97. https://doi.org/10.1016/j.foodcont.2014.12.030

Kirlik, A. (2011). Sociotechnical Systems, Risk and Error. In Human-Tech: Ethical and Scientific Foundations. Oxford University Press.

Kotov, V. (1997). Systems of Systems as Communicating Structures. Social Work in Public Health, 26(1), 1-15. 
Lee, Y. (2014). Global food systems: diet, production, and climate change toward 2050. University of Michigan. University of Michigan. Retrieved from http://deepblue.lib.umich.edu/bitstream/handle/2027.42/108203/Thesis Final Draft for Rackham Submission_1.pdf?sequence=1

Levenstein, H. (1988). Revolution at the table: The transformation of the American Diet. New York: Oxford University Press.

Leveson, N. (2004). A new accident model for engineering safer systems. Safety Science, 42(4), 237-270.

Leveson, N. (2015). A systems approach to risk management through leading safety indicators. Reliability Engineering and System Safety, 136, 17-34. Retrieved from http://dx.doi.org/10.1016/j.ress.2014.10.008

Lien, M. (2004). The Politics of Food: An Introduction. In M. Lien \& B. Nerlich (Eds.), The Politics of Food (1st ed., pp. 1-17). Oxford: BERG.

Long, S., \& Vaughan, L. (2007). Interpersonal Communication. In Encyclopedia of Industrial and Organizational Psychology (pp. 363-366). SAGE Publications, Inc.

Luhmann, N. (1985). A Sociological Theory of Law. (M. Albrow, Ed.) (1st ed.). New York: Routledge and Kegan Paul plc.

Maetz, M. (2013a). Main stakeholders of food and agricultural policies and their motivations. Paris. Retrieved from http://www.hungerexplained.org/Hungerexplained/Stakeholders_files/Stakehold ers_1.pdf

Maetz, M. (2013b). Main stakeholders of food and agricultural policies and their motivations. Paris.

Manning, L. (2017). The Influence of Organizational Subcultures on Food Safety Management. Journal of Marketing Channels, 24(3-4), 180-189. Retrieved from https://doi.org/10.1080/1046669X.2017.1393235

Maynard, T. (2015). Lloyd's Emerging Risk Report - 2015.

Miller, V. (2014). Making EU law into UK law. London. Retrieved from researchbriefings.files.parliament.uk/documents/SN07002/SN07002.pdf

Morowitz, H. (2002). The Emergence of Everything: How the World Became Complex. Oxford University Press.

Nayak, R. (2018). Food Safety Culture: A Systems Approach. Loughborough University. https://doi.org/https://dspace.Iboro.ac.uk/2134/32563

Nayak, R., \& Waterson, P. (2016). 'When Food Kills': A socio-technical systems analysis of the UK Pennington 1996 and 2005 E.coli 0157 Outbreak reports. Safety Science, 86, 36-47. https://doi.org/10.1016/j.ssci.2016.02.007

Nayak, R., \& Waterson, P. (2017). The Assessment of Food Safety Culture: An investigation of current challenges, barriers and future opportunities within the 
1214

1215

1216

1217

1218

1219

1220

1221

1222

1223

1224

1225

1226

1227

1228

1229

1230

1231

1232

1233

1234

1235

1236

1237

1238

1239

1240

1241

1242

1243

1244

1245

1246

1247

1248

food industry. Food Control, 73, 1114-1123.

https://doi.org/10.1016/j.foodcont.2016.10.061

Neff, R., \& Lawrence, R. (2014). Food Systems. In R. Neff (Ed.), Introduction to the US Food System : Public Health, Environment, and Equity (pp. 1-22). John Wiley \& Sons, Incorporated. Retrieved from https://www.planning.org/nationalcenters/health/food.htm

Ottino, J. M. (2004a). Engineering in complex systems. Nature, 427, 399. Retrieved from

http://www.ncbi.nlm.nih.gov/pubmed/24833171\%5Cnhttp://www.ncbi.nlm.nih.go v/pubmed/24056574

Ottino, J. M. (2004b). Engineering in complex systems. Nature, 427, 399.

Pennington, T. (1997). The Pennington Group: Report on the Circumstances Leading to the 1996 Outbreak of Infection with E.coli in Central Scotland, the implications for food safety and the lessons to be learned. Edinburgh. https://doi.org/8 April 1997

Pennington, T. (2009). The Public Inquiry into the September 2005 Outbreak of E.coli 0157 in South Wales.

Pennington, T. H. (2003). When food kills: BSE, E.coli and disaster science (1st ed.). Oxford: Oxford University Press.

Pirog, R., \& Benjamin, A. (2003). Checking the food odometer: Comparing food miles for local versus conventional produce sales to lowa institutions. Leopol Center Pubs and Papers, (July), 8. Retrieved from http://www.leopold.iastate.edu/pubs/staff/files/food_travel072103.pdf

Powell, D. A., Jacob, C. J., \& Chapman, B. J. (2011). Enhancing food safety culture to reduce rates of foodborne illness. Food Control, 22(6), 817-822. Retrieved from http://dx.doi.org/10.1016/j.foodcont.2010.12.009

Randers, J. (2012). 2052. (J. Praded, Ed.) (1st ed.). Vermont: Chelsea Green Publishing.

Rasmussen, J. (1997). Risk management in a dynamic society: A modelling problem. Safety Science, 27(2), 183-213. https://doi.org/10.1016/S09257535(97)00052-0

Rasmussen, J., \& Svedung, I. (2000). Proactive Risk Management in a Dynamic Society. Karlstad: Swedish Rescue Services ... (1st ed.). Boras: Sjujaradsbygdens Tryckeri. Retrieved from http://rib.msb.se/Filer/pdf\%5C16252.pdf

Reiher, C. (2012). Food pedagogies in Japan: From the implementation of the Basic Law on Food Education to Fukushima. Australian Journal of Adult Learning, 52(3), 507-531.

Rocha, L. (1999). Complex Systems Modeling: Using Metaphors From Nature in Simulation and Scientific Models. Retrieved January 21, 2017, from http://www.informatics.indiana.edu/rocha/publications/complex/csm.html 
1249

1250

1251

1252

1253

1254

1255

1256

1257

1258

1259

1260

1261

1262

1263

1264

1265

1266

1267

1268

1269

1270

1271

1272

1273

1274

1275

1276

1277

1278

1279

1280

1281

1282

1283

1284

1285

1286

1287

1288

1289

Salmon, P. M., Read, G. J. M., \& Stevens, N. J. (2016). Who is in control of road safety? A STAMP control structure analysis of the road transport system in Queensland, Australia. Accident Analysis and Prevention, 96, 140-151. https://doi.org/10.1016/j.aap.2016.05.025

Schlosser, E. (2001). Fast Food Nation (1st ed.). Houghton Mifflin.

Simon, H. . (1962). The architecture of complexity. Proceedings from the American Philosophical Society, 106(6), 467-482.

Stanwell-Smith, R. (2013). Just desserts from our poor food safety culture? Perspectives in Public Health, 133(6), 282. Retrieved from http://www.ncbi.nlm.nih.gov/pubmed/24214999

Stoop, J., \& Benner, L. (2015). What do STAMP-based Analysts Expect from Safety Investigations? Procedia Engineering, 128, 93-102. https://doi.org/10.1016/j.proeng.2015.11.508

Svedung, I., \& Rasmussen, J. (2002). Graphic representation of accident scenarios: Mapping system structure and the causation of accidents. Safety Science, 40, 397-417. https://doi.org/10.1016/S0925-7535(00)00036-9

Thatcher, A., Nayak, R., \& Waterson, P. (2019). Human factors and ergonomics systems-based tools for understanding and addressing global problems of the twenty-first century. Ergonomics.

Thatcher, A., \& Yeow, P. H. P. (2016). A sustainable system of systems approach: a new HFE paradigm. Ergonomics, 59(2), 167-178. https://doi.org/10.1080/00140139.2015.1066876

U.S. Food and Drug Administration. (2011). Results Of The FDA-Led Root Cause Investigation Of The Multi-State Listeria Outbreak Related To Jensen Farms Cantaloupe. Retrieved from http://www.fda.gov/downloads/NewsEvents/Newsroom/MediaTranscripts/UCM2 77070.pdf

United States Department of Agriculture Economic Research Service. (2016). Food Availability (Per Capita) Data System. Retrieved from https://www.ers.usda.gov/data-products/food-availability-per-capita-data-system/

Vasquez-Nicholson, J. (2015). UK Supermarket Chain Profiles 2015. Global Agricultural Information Network. London. Retrieved from http://gain.fas.usda.gov/Recent GAIN Publications/UK Supermarket Chain Profiles 2013_London_United Kingdom_12-17-2013.pdf

Vicente, K. J., \& Christoffersen, K. (2006). outbreak: a test of Rasmussen's framework for risk management in a dynamic society. Theoretical Issues in Ergonomics Science, 7(2), 93-112. https://doi.org/10.1080/14639220500078153

Walczak, D., \& Reuter, M. (2002). Relationships : Food Safety and Organizational Behavior. Hospitality Review, 20(1).

Waterson, P., \& Catchpole, K. (2015). Human factors in healthcare: welcome progress, but still scratching the surface. BMJ Quality \& Safetyuality \& Safety, 
1318 Rayner, J. (2018). Brexit provides the perfect ingredients for a national food crisis.

(December), 1-5. Retrieved from http://qualitysafety.bmj.com/content/early/2015/12/18/bmjqs-2015-005074.full

Whaetherill, S. (2009). Report of the Independent Investogator into the 2008 Listeriosis Outbreak. Government of Canada. Canada. https://doi.org/10.1017/CBO9781107415324.004

WHO FERG group. (2015). World Health Day 2015: From farm to plate, make food safe. Retrieved March 31, 2017, from http://www.who.int/mediacentre/news/releases/2015/food-safety/en/

Wilkinson, J. (2004). The food processing industry, globalization and developing countries. Journal of Agricultural and Development Economics, 1(2), 184-201. Retrieved from http://ageconsearch.umn.edu/bitstream/11999/1/01020184.pdf

World Health Organization. (2011). Public Health Review of the Enterohaemorrhagic Escherichia Coli Outbreak in Germany. Regional Office for Europe of the World Health Organization. Retrieved from http://www.euro.who.int/_data/assets/pdf_file/0009/144981/EHEC_outbreak_1 0_June_2011.pdf

WWF. (2016). Living Planet Report 2016: Risk and resilience in a new era. Gland.

\section{Grey literature}

"Constraint". Merriam-Webster (2017). Retrieved 30 April, 2017, from https://www.merriamwebster.com/dictionary/constraint?utm campaign=sd\&utm medium=serp\&utm sour ce=jsonld

Rayner, J. (2017). Michael Gove asked me to a meeting to share my expertise. I declined. Instead, l've given him a piece of my mind. News, [online]. Available at: http://www.jayrayner.co.uk/news/michael-gove-asked-me-to-a-meeting-to-share-myexpertise-i-declined-instead-ive-given-him-a-piece-of-my-mind/ The Observer, [online]. Available at: https://www.theguardian.com/politics/2018/jul/29/no-deal-brexit-food-supply-chaincrisis?CMP=Share iOSApp Other

Reese-Mogg, J. (2018). Is it this May, that May...or the highway? The Sun, p.12.

Rocha, L. (1999). Complex Systems Modeling: Using Metaphors From Nature in Simulation and Scientific Models. Retrieved January 21, 2017, from http://www.informatics.indiana.edu/rocha/publications/complex/csm.html 
Table 1: Development of the food safety law in the UK

\begin{tabular}{|c|c|c|c|c|c|}
\hline Regulation/Act/Development & Year of enactment & Domain & Purpose & Drawback(s) & $\begin{array}{l}\text { Primary targe } \\
\text { population } \\
\text { protection }\end{array}$ \\
\hline $\begin{array}{l}\text { Assisa Panis et Cervisiae (Assize of } \\
\text { Bread and Ale }\end{array}$ & 1266 & Food adulteration & $\begin{array}{l}\text { Medieval English } \\
\text { Law to regulate the } \\
\text { price, weight and } \\
\text { quality of } \\
\text { manufactured beer } \\
\text { and bread. }\end{array}$ & $\begin{array}{l}\text { Did not regulate the } \\
\text { quality of bread and } \\
\text { beer. }\end{array}$ & Consumers \\
\hline \multirow[t]{2}{*}{$\begin{array}{l}\text { Regulation of quality standards } \\
\text { conducted by guilds (corporations of } \\
\text { craftsmen). }\end{array}$} & Middle Ages & Food adulteration & $\begin{array}{l}\text { Market protection } \\
\text { from adulteration. }\end{array}$ & $\begin{array}{l}\text { As guilds were only } \\
\text { present in towns and } \\
\text { cities, adulteration } \\
\text { outside these areas } \\
\text { was unregulated. }\end{array}$ & $\begin{array}{l}\text { Market/Internal } \\
\text { stakeholders }\end{array}$ \\
\hline & & Food adulteration & & $\begin{array}{l}\text { Consumer protection } \\
\text { (if any) was pure } \\
\text { coincidental. }\end{array}$ & \\
\hline $\begin{array}{l}\text { The Treatise on Adulterations of } \\
\text { Food and Culinary Poisons }\end{array}$ & 1820 & Food adulteration & $\begin{array}{l}\text { Book containing list } \\
\text { of all the possible } \\
\text { food adulterants and } \\
\text { adulterers. }\end{array}$ & & Consumers \\
\hline $\begin{array}{l}\text { The Adulteration of Food and Drugs } \\
\text { Act }\end{array}$ & $\begin{array}{l}1860 \text { (revised in } \\
1872 \text { ) }\end{array}$ & Food adulteration & $\begin{array}{l}\text { Provision for the } \\
\text { appointment of } \\
\text { public analysts and } \\
\text { regulations against } \\
\text { food adulteration }\end{array}$ & & Consumers \\
\hline Sale of Food and Drugs Act & 1875 & Food adulteration & $\begin{array}{l}\text { Regulation of sale of } \\
\text { food and drugs. }\end{array}$ & & Consumers \\
\hline Society of Public Analysts & 1874 & Food adulteration & $\begin{array}{l}\text { Official society } \\
\text { consisting of public } \\
\text { analysts }\end{array}$ & & \\
\hline The Milk and Dairies Act & 1914 & Food safety & $\begin{array}{l}\text { Production and sale } \\
\text { of clean and safe } \\
\text { milk for human } \\
\text { consumption }\end{array}$ & & Consumers \\
\hline
\end{tabular}




\begin{tabular}{|c|c|c|c|c|c|}
\hline Regulation/Act/Development & Year of enactment & Domain & Purpose & Drawback(s) & $\begin{array}{l}\text { Primary target } \\
\text { population } \\
\text { protection }\end{array}$ \\
\hline Food and Drugs (Adulterations) Act & 1928 & Food adulteration & $\begin{array}{l}\text { Consolidation of the } \\
\text { Sale of Food and } \\
\text { Drugs Act. }\end{array}$ & & Consumers \\
\hline Food and Drugs Act & 1938 & $\begin{array}{l}\text { Falsifying } \\
\text { information }\end{array}$ & $\begin{array}{l}\text { Introduction of } \\
\text { penalties for false or } \\
\text { misleading labels } \\
\text { and advertising. }\end{array}$ & $\begin{array}{l}\text { Greater focus on } \\
\text { falsifying information } \\
\text { and not enough } \\
\text { focus on food safety } \\
\text { and food } \\
\text { adulteration. }\end{array}$ & Consumers \\
\hline Defence (Sale of Food) Regulations & 1943 & $\begin{array}{l}\text { Food safety and food } \\
\text { adulteration }\end{array}$ & $\begin{array}{l}\text { Crisis plan to ensure } \\
\text { efficient use of } \\
\text { available food. } \\
\text { Detailed information } \\
\text { regarding the } \\
\text { minimum } \\
\text { requirements for } \\
\text { labelling. }\end{array}$ & $\begin{array}{l}\text { No mention about } \\
\text { the need to provide } \\
\text { quantities of } \\
\text { ingredients. }\end{array}$ & Consumers \\
\hline Medicines Act & 1968 & $\begin{array}{l}\text { Food and medicine } \\
\text { safety and } \\
\text { adulteration }\end{array}$ & $\begin{array}{l}\text { Legalisation related } \\
\text { to food and control of } \\
\text { medicines for human } \\
\text { and veterinary use. }\end{array}$ & & Consumers \\
\hline Trade Descriptions Act & 1968 & $\begin{array}{l}\text { Falsifying } \\
\text { information }\end{array}$ & $\begin{array}{l}\text { Prohibition of false } \\
\text { and misleading } \\
\text { advertisement and } \\
\text { product claims, false } \\
\text { indication of the } \\
\text { price of goods and } \\
\text { the false use of royal } \\
\text { awards. }\end{array}$ & $\begin{array}{l}\text { Focus only on } \\
\text { prevention of } \\
\text { falsifying information }\end{array}$ & Consumers \\
\hline Food Act & 1984 & $\begin{array}{l}\text { Intention to cover } \\
\text { food safety, food } \\
\text { adulteration and } \\
\text { falsifying information }\end{array}$ & $\begin{array}{l}\text { Consolidated } \\
\text { previous food safety } \\
\text { provisions }\end{array}$ & $\begin{array}{l}\text { Failed to impose } \\
\text { satisfactory } \\
\text { standards within the } \\
\text { food industry and } \\
\text { was not thorough } \\
\text { enough. Hazard and }\end{array}$ & Consumers \\
\hline
\end{tabular}




\begin{tabular}{|c|c|c|c|c|c|}
\hline Regulation/Act/Development & Year of enactment & Domain & Purpose & Drawback(s) & $\begin{array}{l}\text { Primary target } \\
\text { population } \\
\text { protection }\end{array}$ \\
\hline & & & & $\begin{array}{l}\text { safety were not a } \\
\text { part of this Act. }\end{array}$ & \\
\hline Food Safety Act & 1990 & $\begin{array}{l}\text { Food safety, food } \\
\text { quality and trading } \\
\text { standards }\end{array}$ & $\begin{array}{l}\text { Provides the } \\
\text { framework within } \\
\text { which all modern }\end{array}$ & & Consumers \\
\hline $\begin{array}{l}\text { General Food Law Regulation } \\
\text { (Regulation (EC) No 178/2002) }\end{array}$ & 2002 & $\begin{array}{l}\text { New laws on safety, } \\
\text { traceability, } \\
\text { withdrawal and recall } \\
\text { requirements }\end{array}$ & $\begin{array}{l}\text { food legislation is } \\
\text { written. }\end{array}$ & & \\
\hline General Food Regulation & 2004 & $\begin{array}{l}\text { Further modified the } \\
\text { definition of food as } \\
\text { originally in the Food } \\
\text { Safety Act } 1990\end{array}$ & & & \\
\hline $\begin{array}{l}\text { EU Hygiene Regulations No } \\
852 / 2004,853 / 2004,854 / 2004, \\
2073 / 2005 \text { and } 2075 / 2005 \\
834 / 2007\end{array}$ & 2006 & $\begin{array}{l}\text { Food safety for } \\
\text { different foods and } \\
\text { hazard prevention } \\
\text { within the food } \\
\text { industry }\end{array}$ & $\begin{array}{l}\text { Implementation of } \\
\text { the Hazard Analysis } \\
\text { and Critical Control } \\
\text { Points (HACCP) } \\
\text { system by the } \\
\text { European Union }\end{array}$ & & $\begin{array}{l}\text { Internal and external } \\
\text { stakeholders }\end{array}$ \\
\hline $\begin{array}{l}\text { Official Feed and Food Controls } \\
\text { (England) Regulations } 2009\end{array}$ & 2009 & $\begin{array}{l}\text { Food safety, } \\
\text { agricultural policy, } \\
\text { veterinary and } \\
\text { phytosanitary } \\
\text { measures }\end{array}$ & $\begin{array}{l}\text { Protection of public } \\
\text { health and measures } \\
\text { relating to feed } \\
\text { produced for or fed } \\
\text { to food producing } \\
\text { animals }\end{array}$ & & $\begin{array}{l}\text { Internal and external } \\
\text { stakeholders }\end{array}$ \\
\hline $\begin{array}{l}\text { Regulation (EU) No 1169/2011, } \\
\text { 1924/2006, 609/2013, 1829/2003, } \\
\text { 1830/2003, 1308/2013 }\end{array}$ & 2003-2013 & $\begin{array}{l}\text { Food labelling and } \\
\text { food information, } \\
\text { health and } \\
\text { identification marks }\end{array}$ & $\begin{array}{l}\text { EU food law to } \\
\text { harmonize labelling } \\
\text { of labelling of food } \\
\text { placed on the EU } \\
\text { market. }\end{array}$ & $\begin{array}{l}\text { Changes would need } \\
\text { to be made once the } \\
\text { UK withdraws from } \\
\text { the European Union }\end{array}$ & Consumers \\
\hline $\begin{array}{l}\text { Food Safety and Hygiene (England) } \\
\text { Regulations } 2013\end{array}$ & 2013 & $\begin{array}{l}\text { Certain provisions of } \\
\text { Regulation } 178 / 2002\end{array}$ & $\begin{array}{l}\text { Food safety, food } \\
\text { hygiene, bulk } \\
\text { transport by sea of }\end{array}$ & & Internal stakeholders \\
\hline
\end{tabular}




\begin{tabular}{|c|c|c|c|c|}
\hline Regulation/Act/Development & Year of enactment & Domain & Drawback(s) & $\begin{array}{l}\text { Primary target } \\
\text { population } \\
\text { protection }\end{array}$ \\
\hline & & & $\begin{array}{l}\text { liquid oils, fats and } \\
\text { raw sugar }\end{array}$ & \\
\hline Regulation (EU) 2015/2283 & 2018 & Novel foods & $\begin{array}{l}\text { Import and } \\
\text { manufacture of new } \\
\text { and innovative foods } \\
\text { in the EU market }\end{array}$ & $\begin{array}{l}\text { Internal stakeholders } \\
\text { and consumers }\end{array}$ \\
\hline
\end{tabular}




\section{Characteristics of complex systems}

\section{Purpose}

Efficiency

Order of arrangement

Communication
Defines the system and provides it with integrity to hold it together

Property of the entire system

History of a complex system leads to the constant evolution of the purpose of the system and its behaviours

Complex systems have efficient, short-range and dynamic interactions between elements

It is essential that all the interacting elements are present for efficient functioning of a complex system

The order in which in which the parts of a complex system are arranged affects the performance of the system

Rearranging elements would break the links between interacting elements leading to chaos

Forms the basis of a social system

There are 3 directions of

communication flow:
Top-down

Horizontal

(Bottom-up) Feedback

Direction of communication is from the superior to subordinates Determines how individuals identify with the organisation

Involves passing of information between people at the same hierarchical level

One of the most difficult forms of communication and requires the right amount of information to be passed to avoid inadequate or overcommunication

Feedback helps inform a system about its performance and behaviour positive and negative. Both are necessary to help in the continuous development of the system.

Holism is about looking at the bigger picture and not just addressing the local issues in the subsystem Feedback can be of two types - 
This approach does not just look for simple solutions that address a specific problem, but looks at other linked factors and problems that could arise in the future

\section{Emergence}

Interdependence

Law of requisite variety
Interactions in a complex system leads to the emergence of patterns that define the behaviour of the components/agents within the system and the behaviour of the entire system

Open systems have parts that are related to its whole and to its environment - this is known as interdependence

A change in any part of the system will affect the entire system

Too much variety in a complex system can destroy the entire system

A system would only be able to survive as long as the range of responses it marshals successfully matches the range of situations confronting it 
Table 3: Components of the food system across various systemic levels in the UK and the USA

1342 Adapted from Nayak and Waterson (2016); and Keenan et al., (2015).

\begin{tabular}{|c|c|c|c|}
\hline Systemic level & \multicolumn{2}{|l|}{$\begin{array}{l}\text { Component } \\
\text { United Kingdom }\end{array}$} & Role played in the food system \\
\hline External & \multicolumn{2}{|c|}{$\begin{array}{l}\text { Media, Market forces, Societal values and priorities, Historic events and } \\
\text { Global politics }\end{array}$} & $\begin{array}{l}\text { Conveying new regulations and budget } \\
\text { allocations to consumers as well as } \\
\text { manufacturers; publicizing wrong-doings and } \\
\text { breaches of regulation. Media are essentially the } \\
\text { link between consumers and manufacturers, as } \\
\text { well as consumers and the government. }\end{array}$ \\
\hline \multirow[t]{4}{*}{ Government } & $\begin{array}{l}\text { European commission, Council of } \\
\text { Ministers and European Parliament }\end{array}$ & \multirow[t]{2}{*}{ United States Congress } & Initiation and approval of new laws. \\
\hline & UK Parliament & & $\begin{array}{l}\text { Implementation of regulations in the national food } \\
\text { law; making decisions over how to implement } \\
\text { directives into the country's food regulations; } \\
\text { deciding on budget allocation. }\end{array}$ \\
\hline & Food Standards Agency & $\begin{array}{l}\text { Food and Drug Administration } \\
\text { (FDA) and the Food Safety } \\
\text { Inspection Service (FSIS) }\end{array}$ & $\begin{array}{l}\text { Protection of public health in relation to food; } \\
\text { helping local councils understand food } \\
\text { regulations; making decisions on how to split the } \\
\text { allocated budget. }\end{array}$ \\
\hline & Local councils & $\begin{array}{l}\text { State and local agencies (health } \\
\text { and agriculture departments) }\end{array}$ & $\begin{array}{l}\text { Ensuring that the regulations are actually } \\
\text { implemented; inspecting food businesses; helping } \\
\text { food businesses establish and better themselves. }\end{array}$ \\
\hline \multirow[t]{2}{*}{ Organisational/Workplace } & \multicolumn{2}{|l|}{ Management } & $\begin{array}{l}\text { Conveying information from food inspectors to the } \\
\text { shop-floor employees; ensuring that food } \\
\text { manufactured is safe for consumption; ensuring } \\
\text { that food safety and hygiene regulations are } \\
\text { complied with; administration work; bringing in } \\
\text { orders for the food business; hiring contractors } \\
\text { (cleaning, temporary employees, full-time } \\
\text { employees, transportation); ensuring that } \\
\text { employees have the required training. }\end{array}$ \\
\hline & \multicolumn{2}{|l|}{ Shop-floor employees } & $\begin{array}{l}\text { Working on the shop floor; following training } \\
\text { provided diligently; ensuring that they follow } \\
\text { protocols; making sure that they know what they } \\
\text { are doing; production of food safe for }\end{array}$ \\
\hline
\end{tabular}


Systemic level

Component

United Kingdom
Role played in the food system

United States of America

consumption; efficient cleaning of shop-floor;

transporting food; storing and organizing food in stores. 


\section{Table 4: Common gaps across food safety systems in the UK, US and Europe}

\begin{tabular}{|c|c|c|c|}
\hline $\begin{array}{l}\text { System level (based on the Onion } \\
\text { model) }\end{array}$ & $\begin{array}{l}\text { Example issues within the food } \\
\text { safety domain }\end{array}$ & Current focus & $\begin{array}{l}\text { Gaps in knowledge and the } \\
\text { underexploited aspects }\end{array}$ \\
\hline $\begin{array}{l}\text { Wider physical and virtual work } \\
\text { environment }\end{array}$ & $\begin{array}{l}\text { Food poisoning outbreaks } \\
\text { investigations, food safety related } \\
\text { issues }\end{array}$ & $\begin{array}{l}\text { Root cause analysis, audits and } \\
\text { inspections by food safety inspectors }\end{array}$ & $\begin{array}{l}\text { Adopting proactive measures such } \\
\text { as understanding the food business' } \\
\text { work environment and using these to } \\
\text { support wider organisational } \\
\text { learning. Using methods of incident } \\
\text { investigation (e.g., FRAM) that are } \\
\text { commonly used in other industries } \\
\text { and take into account interactions } \\
\text { between a range of systemic factors } \\
\text { that lead to food poisoning } \\
\text { outbreaks. }\end{array}$ \\
\hline $\begin{array}{l}\text { Personal physical and virtual } \\
\text { workspace }\end{array}$ & Safety culture & $\begin{array}{l}\text { Survey instruments, benchmarking, } \\
\text { microbial testing, rapid testing } \\
\text { techniques }\end{array}$ & $\begin{array}{l}\text { Qualitative methods provide richer } \\
\text { assessments of the safety culture of } \\
\text { food businesses; multiple methods } \\
\text { should be used to assess the safety } \\
\text { culture (e.g., interviews with staff, } \\
\text { questionnaires, workshops) }\end{array}$ \\
\hline Tasks & $\begin{array}{l}\text { Demands, decision making, } \\
\text { workload, situational awareness }\end{array}$ & $\begin{array}{l}\text { Focus on mistakes and blame } \\
\text { culture }\end{array}$ & $\begin{array}{l}\text { Use of cognitive work analysis to get } \\
\text { deeper insights into how complex } \\
\text { tasks and team work are } \\
\text { accomplished. Understanding } \\
\text { antecedents (early warning, near } \\
\text { misses) that lead to negative } \\
\text { behaviours. }\end{array}$ \\
\hline People & $\begin{array}{l}\text { Team work, temporary agency } \\
\text { workers }\end{array}$ & $\begin{array}{l}\text { Team training and making every } \\
\text { employee understand company } \\
\text { protocols and the health and safety } \\
\text { protocols }\end{array}$ & $\begin{array}{l}\text { Understanding staff better to help } \\
\text { them achieve job satisfaction, } \\
\text { ensuring that the workload is no too } \\
\text { much and making sure that the team } \\
\text { is able to achieve everything } \\
\text { together (socio-cultural aspects of } \\
\text { team work - trust and organisational } \\
\text { commitment). }\end{array}$ \\
\hline Technology & $\begin{array}{l}\text { Temperature control thermometers, } \\
\text { rapid hygiene testing devices }\end{array}$ & Usability, reliability and validity & $\begin{array}{l}\text { Understanding the impact of } \\
\text { technology on working practice }\end{array}$ \\
\hline
\end{tabular}




\begin{tabular}{|c|c|c|c|}
\hline $\begin{array}{l}\text { System level (based on the Onion } \\
\text { model) }\end{array}$ & $\begin{array}{l}\text { Example issues within the food } \\
\text { safety domain }\end{array}$ & Current focus & $\begin{array}{l}\text { Gaps in knowledge and the } \\
\text { underexploited aspects }\end{array}$ \\
\hline Tools & $\begin{array}{l}\text { Hazard Analysis and Critical Control } \\
\text { Points (HACCP) used globally; Safer } \\
\text { Food Better Business (SFBB) and } \\
\text { Food Hygiene Rating Scheme } \\
\text { (FHRS) in the UK; the FDA-iRisk® } \\
\text { and Virtual Deli in the US; the Rapid } \\
\text { Alert System for Food and Feed } \\
\text { (RASFF) used in the European } \\
\text { Union. }\end{array}$ & Compliance, standardisation & $\begin{array}{l}\text { Involving stakeholders while } \\
\text { designing the implementation } \\
\text { process in order to provide } \\
\text { appropriate local solutions. } \\
\text { Understanding that tools are } \\
\text { complex interventions that depend } \\
\text { on other system attributes (e.g., } \\
\text { communication, culture) }\end{array}$ \\
\hline
\end{tabular}




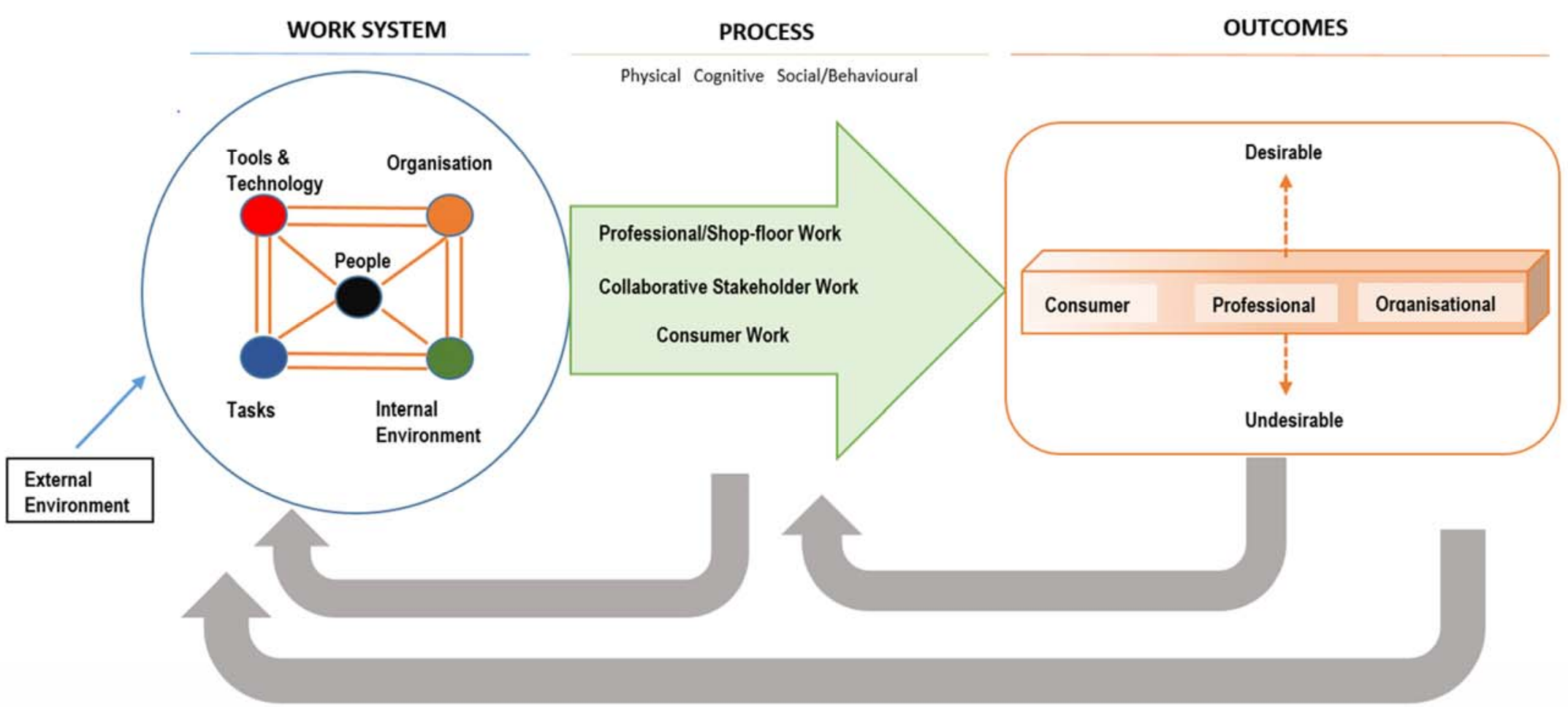

Anticipated or unanticipated Short-or long-lasting Intermittent or regular 
1349 Figure 2: Boundaries of acceptable behaviour

1350 Adapted from Rasmussen (1997)

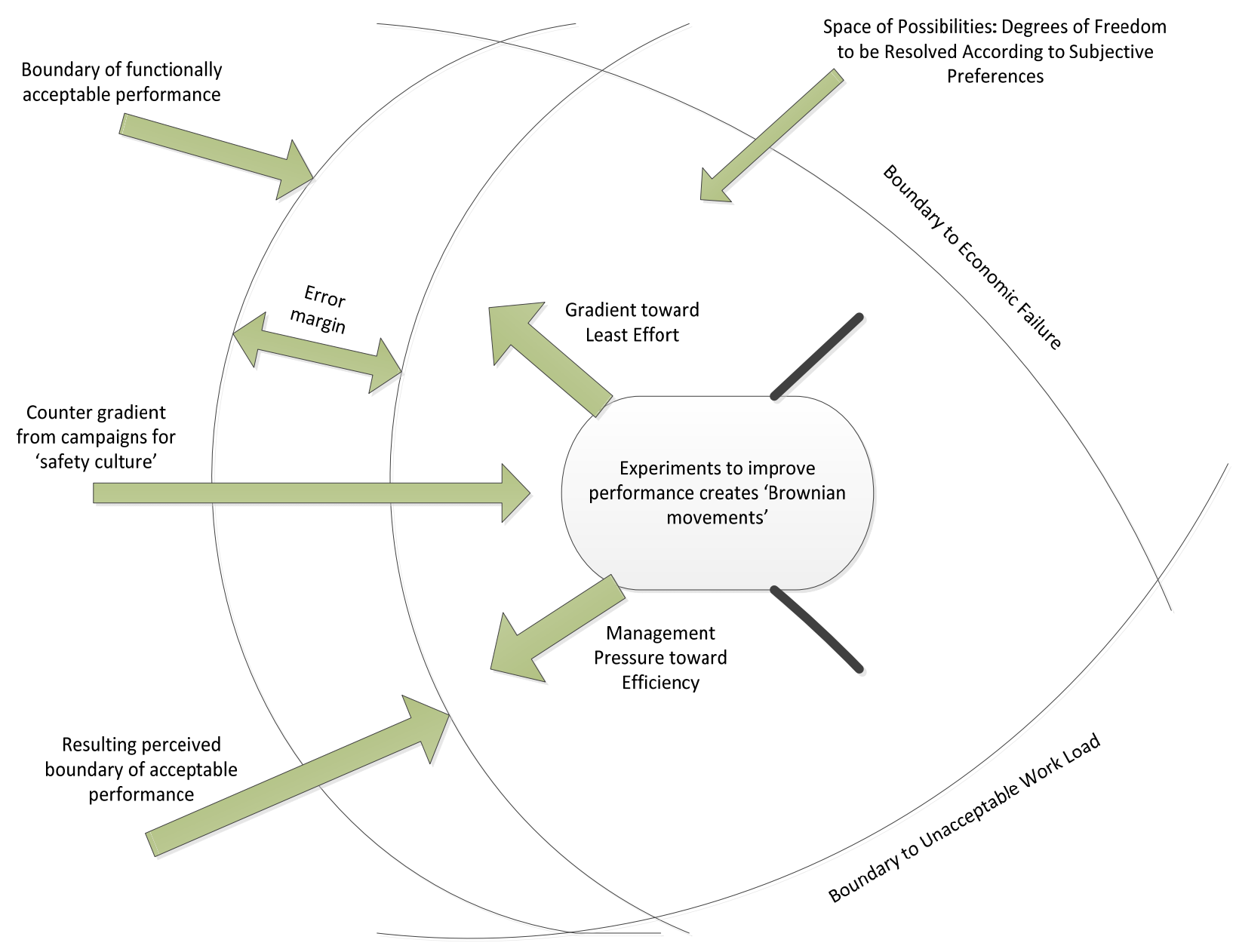


Figure 3: General form of a STAMP model

1353 Adapted from Leveson (2004) p. 257.

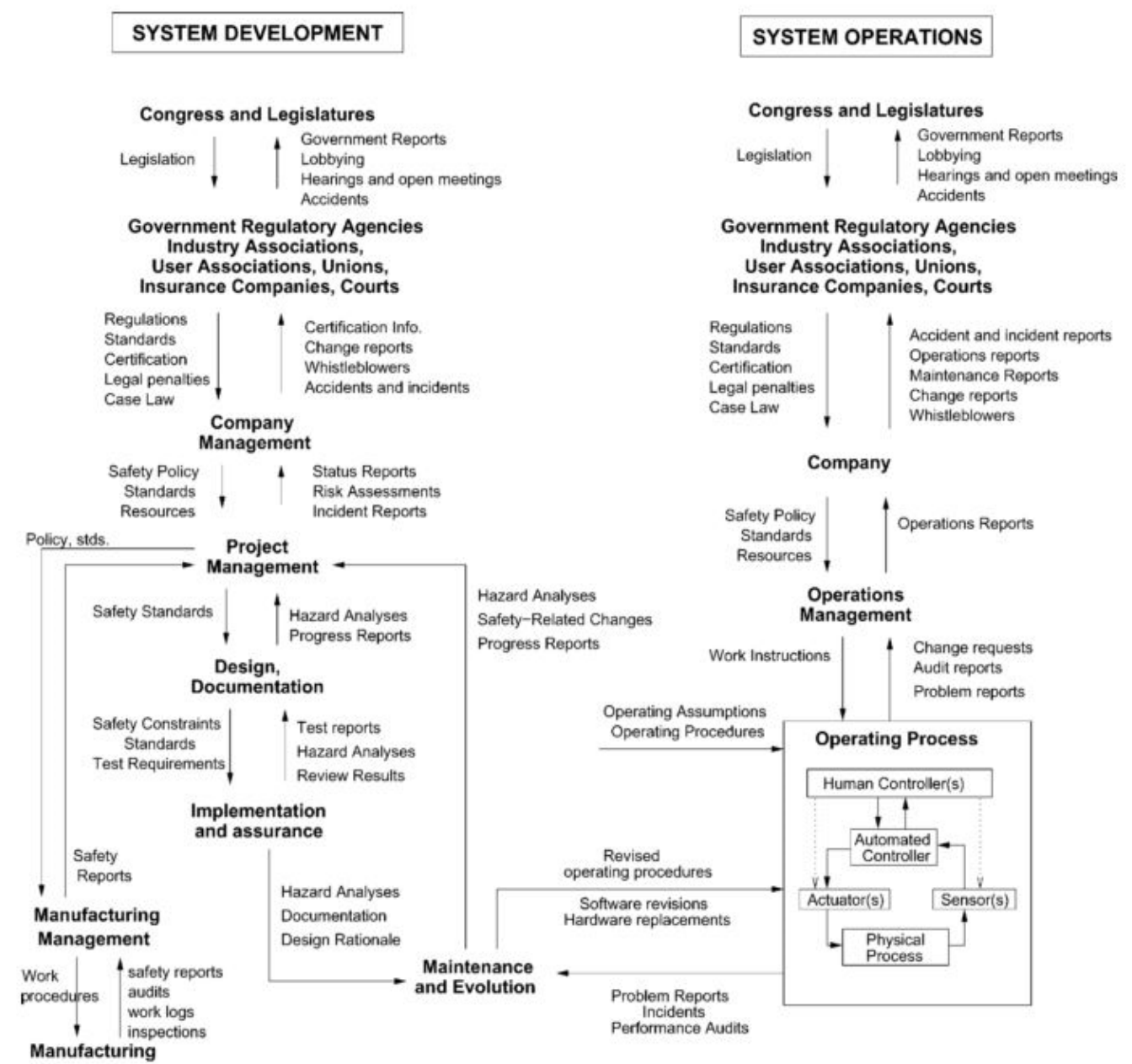


1356 Figure 4: An example STAMP model of the control and feedback structure of the UK food system

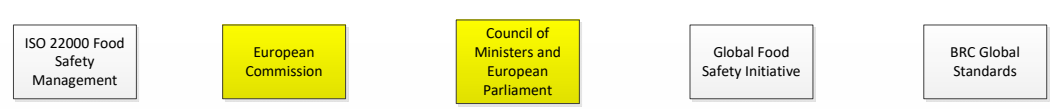

